\title{
23 The Treated Thorax in Patients with Hematological Malignancies
}

\author{
Benoît Mesurolle, Nobuyuki Tanaka, John Kosiuk, François Mignon, Sylvain Choquet
}

\section{CONTENTS}

23.1 Introduction 443

23.2 Chest Complications Associated with Chemotherapy 444

23.2.1 HSCT non-Specific Complications 444

23.2.1.1 Infectious Conditions 444

23.2.1.1.1 Bacterial Pneumonia 445

23.2.1.1.2 Pneumocystis carinii Pneumonia 445

23.2.1.1.3 Fungal Infections 446

23.2.1.1.4 Tuberculosis 448

23.2.1.2 Drug Toxicity 449

23.2.1.3 Pulmonary Hemorrhage 450

23.2.2 HSCT Specific Complications 451

23.2.2.1. Infectious Conditions 451

23.2.2.1.1 Cytomegalovirus Pneumonia 452

23.2.2.2 Pulmonary Edema 452

23.2.2.3 Idiopathic Pneumonia Syndrome 452

23.2.2.4 Bronchiolitis Obliterans 454

23.2.2.5 Bronchiolitis Obliterans Organizing Pneumonia 455

23.3 Post Radiation Changes 456

23.3.1 Lung Injuries 456

23.3.1.1 Radiation Pneumonitis and Fibrosis 456

23.3.1.2 Spontaneous Pneumothorax 458

23.3.2 Mediastinal Changes 458

23.3.2.1 Thymic Cysts 458

23.3.2.2 Calcified Lymph Nodes 458

Benoît Mesurolle, MD

Assistant Professor, McGill University Health Center, Department of Radiology, Royal Victoria Hospital, 687 Pine Avenue West, Montreal PQ, H3A 1A1, Canada

NobuYuki TANAKa, MD

Assistant Professor, Chest Radiologist, Department of Radiology, Yamaguchi University School of Medicine, 1-1-1 Minamikogushi, Ube, Yamaguchi 755-8505, Japan

John Kosiuk, MD

Assistant Professor, McGill University Health Center, Department of Radiology, Royal Victoria Hospital, 687 Pine Avenue West, Montreal PQ, H3A 1A1, Canada

François Mignon, MD

Assistant Professor, Department of Radiology, Versailles Hospital Center, 177 Rue de Versailles, 78157 Le Chesnay Cedex, France

Sylvain Choquet, MD

Assistant Professor, Department of Hematology, Versailles Hospital Center, 177 Rue de Versailles, 78157 Le Chesnay Cedex, France
23.3.2.3 Benign Esophageal Injuries 458

23.3.3 Cardiovascular Injuries 460

23.3.3.1 Vascular Injuries 460

23.3.3.2 Coronary Artery Disease 460

23.3.3.3 Calcified Ascending Aorta 461

23.3.3.4 Pericardial Disease 461

23.3.3.5 Valvular Injuries and Conduction Abnormalities 461

23.3.4 Chest Wall and Nerve Injuries 462

23.3.4.1 Radiation-Induced Brachial Plexopathy 462

23.3.4.2 Left Sided Vocal Cord Paralysis 462

23.3.4.3 Aseptic Necrosis and Osteochondroma 462

23.4 Second Solid Neoplasms 463

23.4.1 Mesothelioma, Lung and

Esophageal Carcinomas 463

23.4.2 Breast Carcinoma 463

23.4.3 Sarcomas 463

23.4.3.1 Diagnosis of Radiation-Induced Bone Sarcoma 464

23.4.3.2 Factors Related to Radiation-Induced

Sarcomas 464

23.4.3.3 Imaging Appearance 464

23.5 Residual Masses and Thymic Rebound 465

23.5.1 Residual Mediastinal Masses 465

23.5.2 Thymic Rebound Hyperplasia 466

23.6 Transfusion-Related Acute Lung Injury 466

23.7 Conclusion 468

References 469

\section{1}

\section{Introduction}

Thoracic complications and changes are frequent in patients with hematological malignancies. In those patients with advanced hematological malignancies pulmonary complications, mostly related to chemotherapy, can be a leading cause of death. Tenholder and Hooper found that $98 \%$ of leukemic patients showed pulmonary complications at autopsy (TenHOLDER and Hooper 1980). Of note however, in recent years the frequency of radiation-induced complications has decreased. As the number of survivors increases, several late effects of treatment are becoming evident, some of them - second malignancies, cardiovascular complications - emerging as a major threat to the survival of these patients. To offer the best in patient care, it is imperative to understand the natural history of the 
disease as well as the treatment related complications and changes. In this chapter, post-therapeutic thoracic changes after chemotherapy and radiation therapy are discussed and illustrated.

\section{2 \\ Chest Complications Associated with Chemotherapy}

Although chest radiography is an important modality, the findings are often nonspecific or difficult to detect. High-resolution CT (HRCT) is a powerful tool for the detection of early or tiny pulmonary lesions occurring in immunocompromised patients. With progressive improvement in therapy for patients with hematological malignancies, hemopoietic stem cell transplantation (HSCT) has become a standard method for treating aggressive disorders. The frequency of pulmonary complications is different in patients who have undergone HSCT and those who have not. These complications can be divided into two categories: complications not specific to patients treated with HSCT (HSCT non-specific complications) and complications specific to patients treated with HSCT (HSCT specific complications occur in approximately $50 \%$ of transplant recipients) (Worthy et al. 1997a).
Stem cells may be obtained from the patients themselves (autologous HSCT) or from related or unrelated donors (allogeneic HSCT), and may be harvested in the form of bone marrow, peripheral blood stem cells or, less frequently, cord blood (Hows 2001). Autologous HSCT complications are directly related to the conditioning regimen (chemotherapy with or without total body irradiation). Allogeneic HSCT adds the toxicity of the conditioning regimen to a major immunosuppression and, often, graft versus host disease (GVHD). Allogeneic HSCT specific complications occur in a characteristic temporal pattern associated with the period following the procedure (WORTHY et al. 1997a). The period after HSCT is divided into 3 phases: neutropenic, early and late (Fig. 23.1).

\subsection{1 \\ HSCT non-Specific Complications}

\subsubsection{1}

\section{Infectious Conditions}

Sixty to $75 \%$ of reported deaths in leukemia, after HSCT, are due to infectious diseases (HILDEBRAND et al. 1990). Such infectious conditions tend to occur after chemotherapy or in the neutropenic or early phase following HSCT.

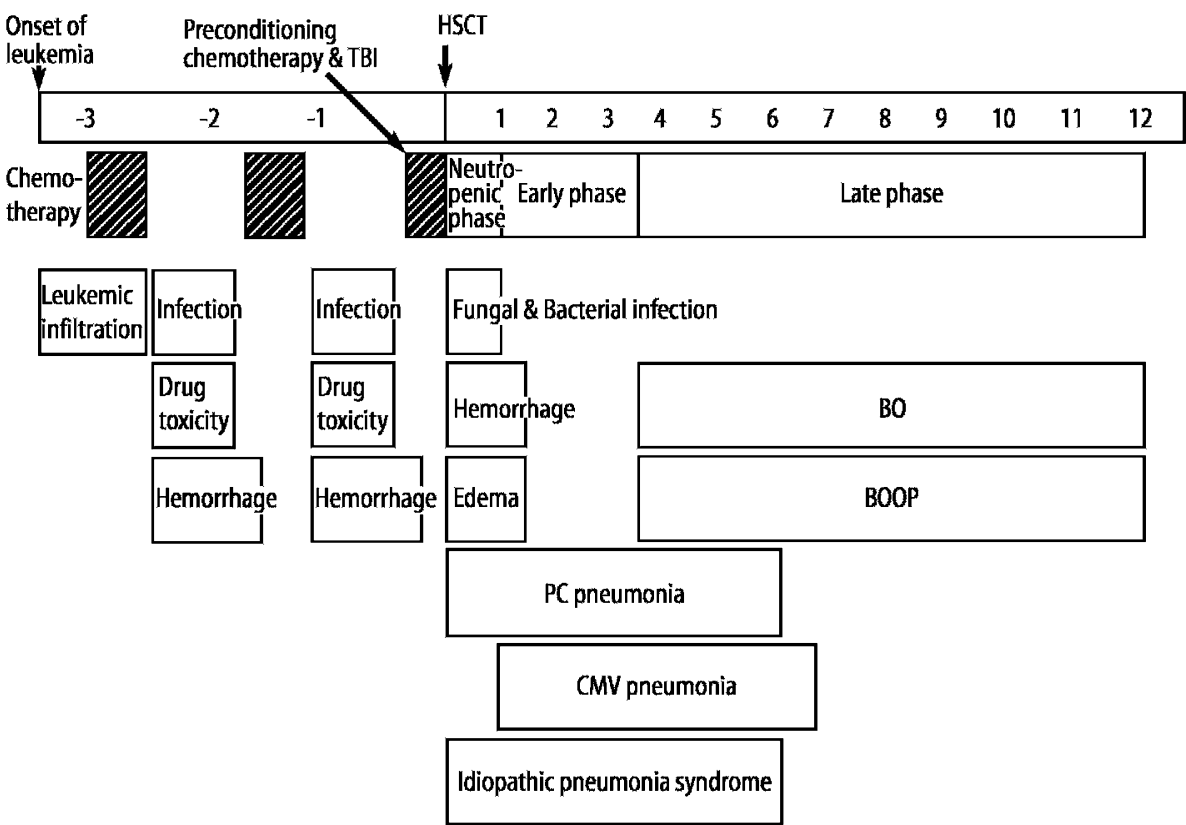

Fig. 23.1. Pulmonary effects of treatment in patients with hematological malignancies. Pulmonary complications often occur in a characteristic temporal pattern associated with hemopoietic stem cell transplantation. (With permission from [TANAKA et al. 2002]) 


\subsubsection{1}

\section{Bacterial Pneumonia}

Granulocytopenia is a major predisposing factor for bacterial infections. This condition occurs after chemotherapy, with or without HSCT. Bacterial pneumonia in HSCT recipients occurs usually in the neutropenic phase, and its incidence is estimated as 20 to $50 \%$ (SoubANi et al. 1996). Gram-negative organisms presumably, from the gastro-intestinal tract or oral mucosa, are classically considered as the predominant group of bacteria, but recent studies show that gram-positive infections represent 60 to $70 \%$ of isolated organisms, mainly Staphylococcus aureus and coagulase negative Staphylococcus (ZinNer 1999). Defective function of the mucociliary system caused by bronchial sicca-like damage from GVHD, impaired production of secretory IgA, abnormal humoral response to pneumococcal polysaccharide antigen, and spleen dysfunction (caused by total body irradiation and/or allogeneic HSCT) are responsible for the increased frequency of these infections.

In bacterial pneumonia, airspace consolidation or ground-glass opacity with centrilobular, acinar, and lobular opacities is observed. Ground-glass opacity seems to occur more frequently in immunocompromised patients than in immunocompetent patients (Fig. 23.2). Winn and Chandler (1994) reported that, because the diminution of the inflammatory change in the immunocompromised host was perhaps caused by neutropenia, the radiographic findings were markedly altered by the minimal inflammation. There may be a tendency to produce ground-glass opacity or small opacities like centrilobular opacities on HRCT because the exudative reaction in immunodeficiency states is minimal.

\subsubsection{2}

\section{Pneumocystis carinii Pneumonia}

Pneumocystis carinii pneumonia occurs in patients with hematological malignancies who undergo intensive chemotherapy, especially with corticoid and fludarabine, or HSCT. In our institution, it occurs less frequently in HSCT recipients, probably because of the introduction of routine prophylaxis with sulfamethoxazole/trimethoprim. The incidence of Pneumocystis carinii pneumonia in HSCT recipients is reported as less than 10\% (SoubANI et al. 1996). Characteristic pathologic findings include intraalveolar histiocytes or a mixture of inflammatory infiltrates with or without associated hemorrhage. The

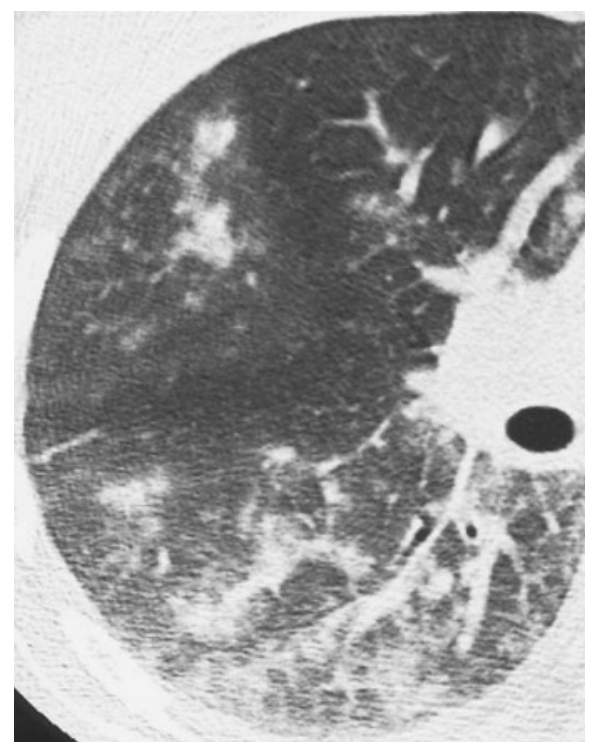

Fig. 23.2. Bacterial pneumonia in a 25 -year-old woman with acute lymphocytic leukemia. Axial HRCT scan shows widespread ground-glass opacities and patchy acinar or centrilobular opacities mainly along the bronchovascular bundles.

classic chest radiographic finding of Pneumocystis carinii pneumonia is a bilateral perihilar or diffuse symmetric interstitial pattern, which may be finely granular, reticular, or ground-glass in appearance. Chest radiography may have normal or nonspecific findings at the time of initial examination in as many as $40 \%$ of cases. In a study of 51 cases with a high clinical suspicion of Pneumocystis carinii pneumonia in which chest radiography showed normal, equivocal or non-specific findings by GRUDEN et al. (1997), Pneumocystis carinii pneumonia was detected in six of 51 cases. The findings were confirmed by HRCT, which showed abnormal findings in all six cases. It is evident that HRCT is needed for the detection of early lesion of Pneumocystis carinii pneumonia when it is strongly suspected in the clinical setting.

On HRCT, widespread ground-glass opacity, which is typically distributed at the perihilar regions, is a frequent and characteristic finding (Fig. 23.3) (WebB et al. 1996; Kuhlman et al. 1990). Extensive ground-glass opacity is usually observed with sparing of adjacent secondary pulmonary lobules, called a mosaic or geographic pattern. Occasionally, reticulation or intralobular and interlobular septal thickening within ground-glass opacity may be recognized (crazy-paving appearance), presumably reflecting a combination of fluid and cellular components within the alveolar space as well as thickening of the alveolar septa. Centrilobular opaci- 

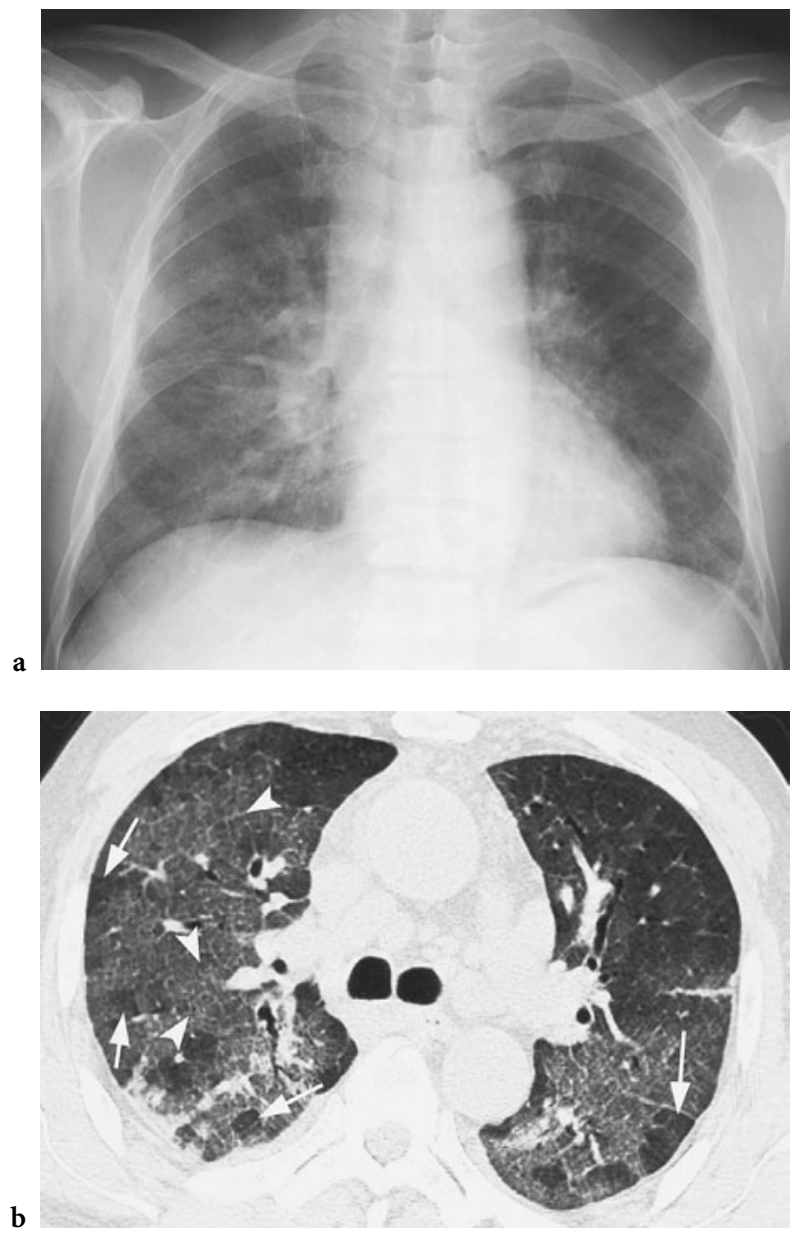

Fig. 23.3a,b. Pneumocystis carinii pneumonia in a 60-yearold man with acute lymphocytic leukemia. a Posteroanterior chest radiograph shows mixed interstitial and alveolar disease with a right lower lobe predominance. Bilateral hilar and mediastinal lymphadenopathies are also noted. b Axial HRCT scan shows widespread ground-glass opacity with sparing of adjacent pulmonary lobules (arrows), creating a mosaic pattern. Note the reticular opacities within ground-glass opacity, showing "crazy-paving appearance" (arrowheads).

ties or Y-shaped branching structures (tree-in-bud appearance) are sometimes observed, corresponding to bronchiolitis and bronchioles impacted with inflammatory material (WeBв et al. 1996; BoISELLE et al. 1999). In addition to these classical HRCT findings, other atypical findings have been reported in patients with AIDS, such as cystic lesions, upper lobe distribution, lung nodules or masses, lobar consolidation or interstitial fibrosis (BoISELLE et al. 1999). However, we have never encountered such atypical findings in patients with hematological malignancies in our institution.

\subsubsection{3}

Fungal Infections

Fungal infection is a common cause of pneumonia in HSCT recipients. However, it also occurs in patients who do not undergo HSCT. In our series, it occurred more frequently in patients who without HSCT. Granulocytopenia is the most important risk factor (Hildebrand et al. 1990). In HSCT recipients, it usually occurs in the neutropenic phase. The pathogens are Aspergillus, Candida, Cryptococcus, and Mucor. The most common pathogen in this entity is Aspergillus. In general, infection due to Aspergillus frequently occurs when the peripheral white blood count decreases to less than $1,000 / \mathrm{mm}^{3}$. Invasive pulmonary aspergillosis is the most frequent pattern of infection caused by Aspergillus in immunocompromised patients.

Characteristic chest radiographic findings include solitary or multiple focal opacities or consolidation distributed in the peripheral lung. Detection of early lesions of invasive aspergillosis is rather difficult because about one quarter of patients with invasive pulmonary aspergillosis show no abnormal chest radiographic findings. CT is needed in the early diagnosis of invasive pulmonary aspergillosis. Invasive pulmonary aspergillosis includes two types: angio-invasive aspergillosis (angio-invasive pulmonary aspergillosis) and airway-invasive aspergillosis (airway-invasive pulmonary aspergillosis). Usually, invasive pulmonary aspergillosis means angio-invasive pulmonary aspergillosis.

Angio-invasive pulmonary aspergillosis presents two characteristic CT findings: CT-halo sign, an early sign after infection (Fig. 23.4) and the air crescent sign, observed in relatively late phase of infection (KunLman et al. 1988). The CT-halo sign is observed at the period of neutropenia, and represents a hemorrhagic infarction, in which the nodular lesion corresponds to a gray-yellow necrotic center, and the ground-glass opacity to a rim of hemorrhage caused by thrombosis of fungi within pulmonary vessels. This sign was first reported by KuHLman et al. (1985) and thought to be characteristic and specific to invasive pulmonary aspergillosis. However, it has been reported in patients with hemorrhagic nodules in the lung, such as candidiasis, CMV infection, Wegener granulomatosis and metastatic angiosarcoma (PrIMACK et al. 1994). The air crescent sign is observed at the period when neutropenia is recovering and represents the cavitation of nodules caused by resorption of necrotic tissue by returning neutrophils (Fig. 23.5) (TANAKA et al. 2002). This sign is usually 


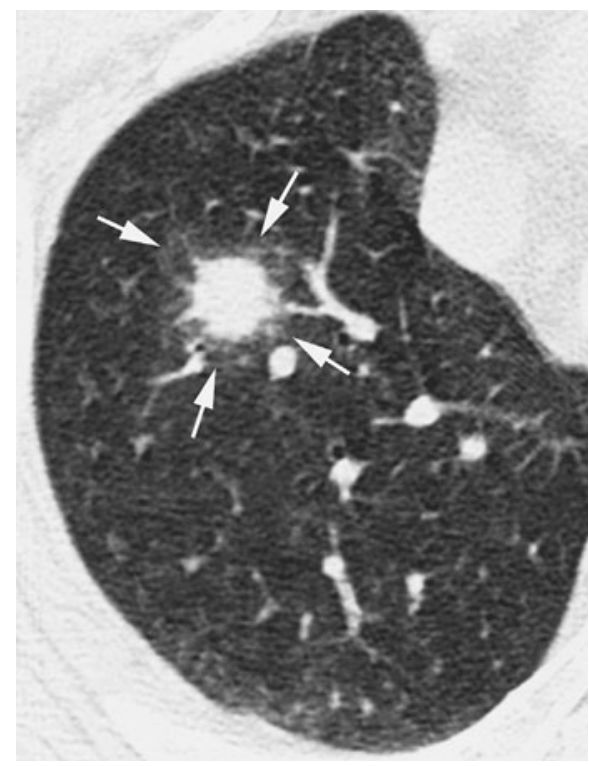

Fig. 23.4. Invasive aspergillosis in a 58-year-old man with chronic myelocytic leukemia. Axial HRCT scan shows a central hyperdense nodule with surrounding halo of groundglass opacity (CT-halo sign) (arrow) in the right upper lobe. (With permission from [TANAKA et al. 2002])

observed 2-3 weeks after infection. Therefore, it is not useful as an early indication of invasive pulmonary aspergillosis. However, the existence of air crescent sign suggests that the patient is in the recovery phase from infection because it is not seen in patients who do not recover from neutropenia. In a report by GeFTER et al. (1985), the air crescent sign was associated with a good prognosis. We treated a case with extensive ground-glass opacity on CT images induced by the invasion of Aspergillus into pulmonary arteries and subsequent pulmonary infarction (Fig. 23.6). The ground-glass opacity was caused by the hemorrhagic changes. It must be noted that extensive pulmonary alveolar hemorrhage can be induced by fungal infection as well as thrombocytopenia or HSCT.

There are few reports concerning airway-invasive pulmonary aspergillosis. It may be seen in $10-30 \%$ of patients with invasive pulmonary aspergillosis. Chest radiography shows non-specific findings indicating bronchopneumonia. Pathological findings of airwayinvasive pulmonary aspergillosis include bronchiolitis and bronchopneumonia caused by Aspergillus. CT findings may show small centrilobular nodules and peribronchial airspace consolidation, which reflect the pathological findings. However, these CT findings are non-specific, and it is difficult to differentiate this entity from other infectious diseases.

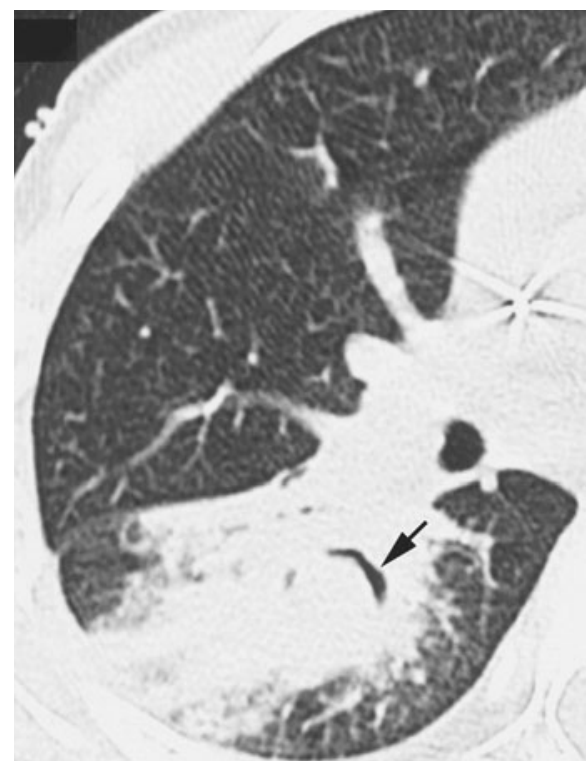

Fig. 23.5. Invasive aspergillosis in a 47-year-old man with acute myelocytic leukemia. Axial HRCT scan shows airspace consolidation with a crescent-like cavity (air crescent sign) (arrow) in the right lower lobe.

Candidiasis frequently occurs concomitantly with bacterial infection, and the characteristic radiographic findings of pulmonary candidiasis are difficult to describe. In the report of a radiographic-pathologic correlative study of candidiasis by Dubois et al. (1977), lesions were divided into hematogenous and endobronchial spread. In the former, hemorrhagic nodules are the characteristic pathologic finding. Central areas of necrosis and surrounding hemorrhage are observed. These findings are nearly identical to those of angio-invasive pulmonary aspergillosis (CT-halo sign). Nodules seen in patients with candidiasis are usually smaller than those in invasive pulmonary aspergillosis (Fig. 23.7), therefore, these nodules may be difficult to detect by chest radiography. Miliary nodules may sometimes be seen but in a report of 20 cases of pulmonary candidiasis by BuFf et al. (1982), there were no cases showing a miliary nodular pattern. In the latter type of endobronchial spread, bronchopneumonia is the radiological and pathologic finding.

Cryptococcosis, especially secondary cryptococcosis shows solitary or multiple pulmonary nodules or infiltrative opacities. These lesions may sometimes cavitate. In a CT report of 10 cases with AIDS by Sider and WestcotT (1994), five patients had segmental airspace consolidation with air broncho- 

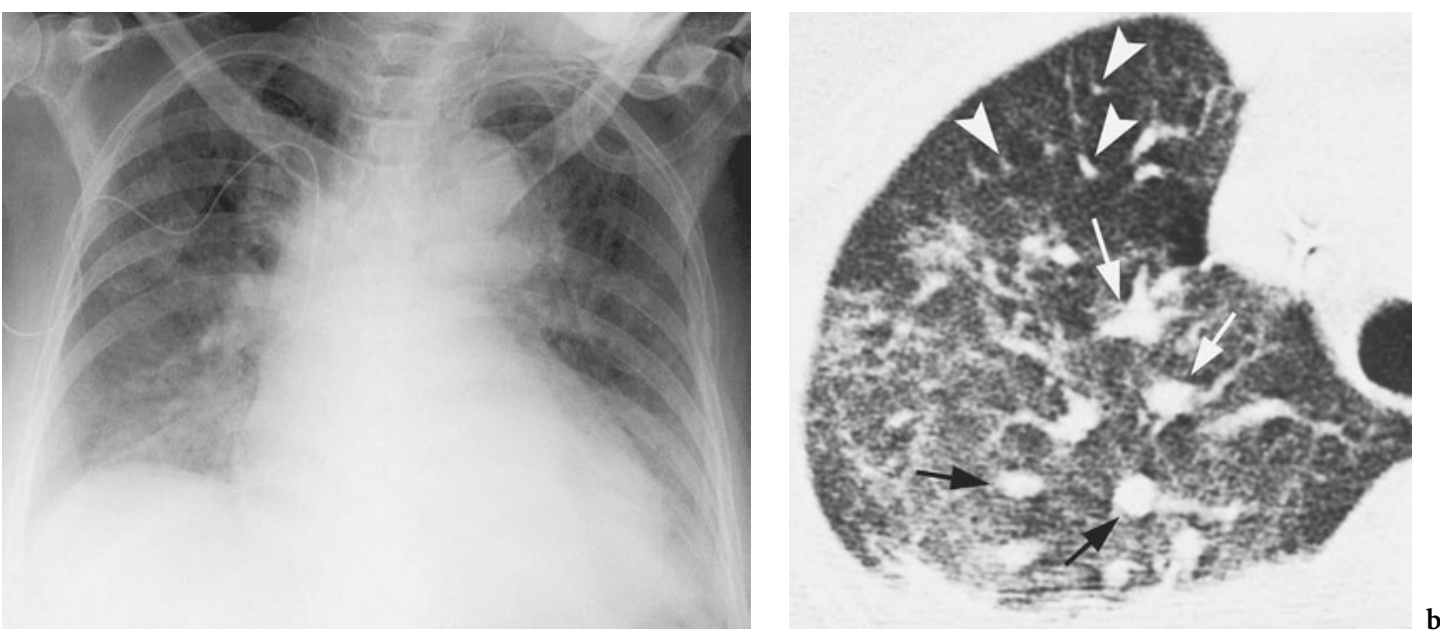

Fig. 23.6a,b. Mycotic thrombosis in a 70-year-old man with plasma cell leukemia. a Posteroanterior chest radiograph shows diffuse bilateral air space disease and cardiomegaly. b Axial HRCT scan shows extensive ground-glass opacity with pleural effusion in the right upper lobe. Note that the diameter of pulmonary arteries within the ground-glass opacity became wider (arrows) compared with those in the normal lung (arrowheads). This patient died after the CT examination. Specimens obtained at autopsy showed extensive hemorrhage and hemorrhagic infarction induced by extensive mycotic (Aspergillus) thrombosis within pulmonary arteries.

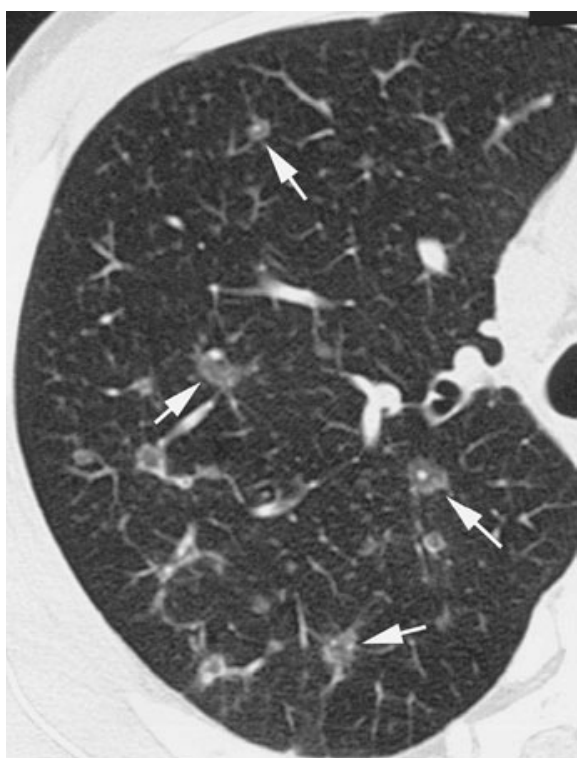

Fig. 23.7. Candidiasis in a 28 -year-old man with natural killerlike T-cell leukemia. Axial HRCT scan shows multiple nodules with surrounding ground-glass opacities (arrows).

gram, five had ground-glass opacity distributed at the perihilar or lower lung regions, and three had multiple nodules with indistinct borders. It may also be difficult to distinguish cryptococcosis from other infectious conditions based on these reported CT findings.
The CT findings of mucormycosis are indistinguishable from those of invasive pulmonary aspergillosis. Multiple nodules or airspace consolidation are frequent. It should be noted that the CT-halo sign is frequently observed due to hemorrhagic infarction based on the angio-invasive nature of Mucor just as with invasive pulmonary aspergillosis (MCADAMs et al. 1997). Cases with pseudoaneurysm or invasive change into the thoracic spine have been reported.

There is an unusual condition induced by the specific nature of fungi including Aspergillus and Mucor. Hypoxemia without apparent abnormal CT findings may sometimes be observed in patients with fungal infection. This condition seems to be induced by intravascular fungal emboli (Fig. 23.8). The mechanism is the same as that in patients with leukostasis, which is characterized by intravascular leukemic cell emboli due to high leukocyte count (MCKeE et al. 1974).

\subsubsection{4}

Tuberculosis

Pulmonary tuberculosis in immunocompromised patients often has an atypical CT pattern compared with that in immunocompetent patients; it includes non-segmental distribution and multiple small cavities within lesions (IKezoe et al. 1992). Numerous small nodules with random distribution 


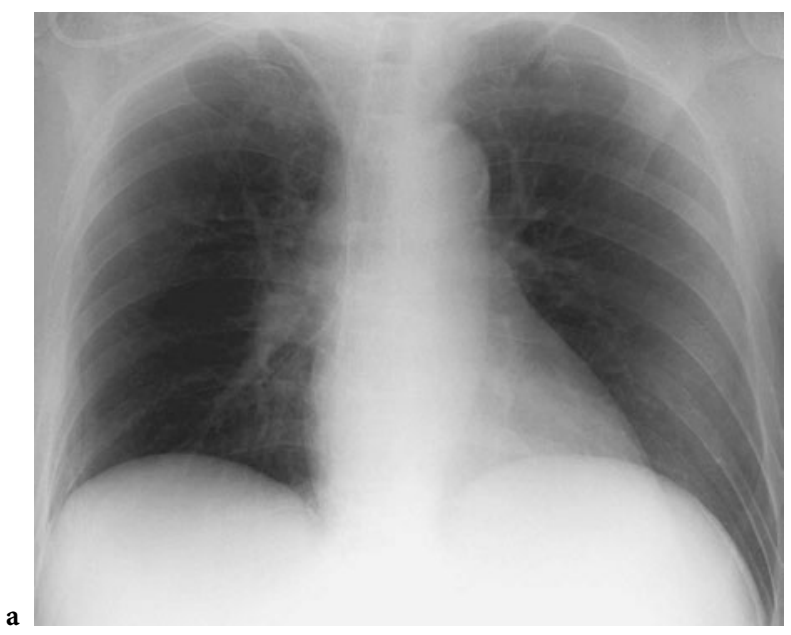

Fig. 23.8a-c. Mycotic thrombosis in a 55-year-old woman with chronic myelocytic leukemia. a Posteroanterior chest radiograph shows no abnormal finding. b Axial HRCT scan appears almost normal except for linear-reticular opacities in the right lower lobe. This patient showed severe hypoxia and died one week after CT examination. c Autopsied specimen shows thrombus with Candida filling the pulmonary artery and arterioles.

within secondary pulmonary lobules are a characteristic HRCT finding for miliary tuberculosis $(\mathrm{OH}$ et al. 1994). Ground-glass opacity may be present along with nodules (Fig. 23.9) (TANAKA et al. 2002). Ground-glass opacity corresponds pathologically to widespread interstitial granuloma of a size below the limits of resolution on HRCT (OH et al. 1994).

\subsubsection{2}

\section{Drug Toxicity}

Drug-induced lung diseases must always be considered in the differential diagnosis of pulmonary infiltrates in immunocompromised patients who are undergoing chemotherapy, even though the exact incidence is uncertain.

Rossi et al. (2000) reported radiographic findings of drug toxicity based on pathologic findings. As possible pathologic manifestations of pulmonary drug toxicity, they mentioned diffuse alveolar damage, nonspecific interstitial pneumonia, bronchiolitis obliterans organizing pneumonia (BOOP), eosinophilic pneumonia, and others. Diffuse alveolar damage is recognized as a common manifesta-
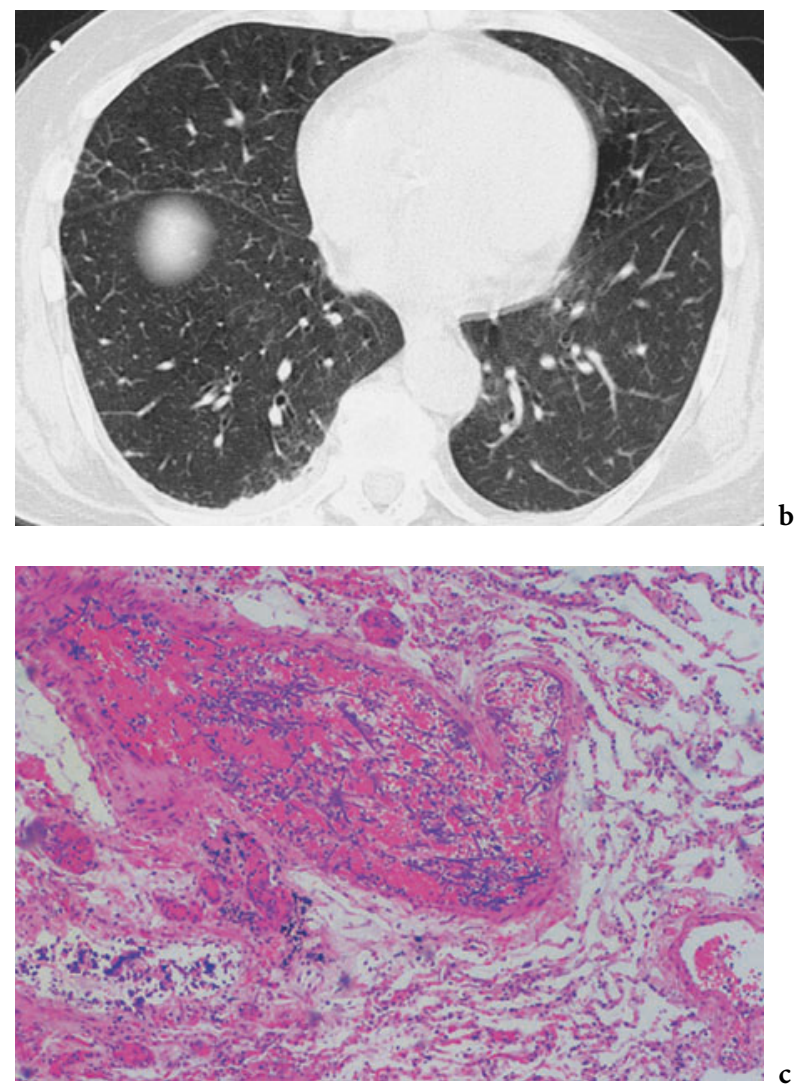

tion of drug toxicity, and chest radiograph findings include bilateral heterogeneous or homogeneous opacities, often in a mid and lower lung distribution. HRCT shows scattered or diffuse areas of groundglass opacity. With the progression of lesions, fibrosis, architectural distortion or honeycombing may occur. The concept of nonspecific interstitial pneumonia is relatively new and is thought to be a second most frequent entity among idiopathic interstitial pneumonia. Rossi et al. (2000) found this pattern to be the most frequent in interstitial pneumonia in patients with pulmonary drug toxicity. Nonspecific interstitial pneumonia is characterized pathologically by areas of expansion of the interstitium by mononuclear inflammatory cells and mild interstitial pneumonia with temporal and spatial homogeneity. Interstitial inflammation is typically more cellular than that seen in idiopathic interstitial pneumonia. Chest radiography usually shows diffuse heterogeneous opacities. HRCT shows scattered or diffuse areas of ground-glass opacity. BOOP is a nonspecific pathologic pattern of lung injury that can be a manifestation of pulmonary drug toxicity, characterized by proliferation of immature fibroblas- 

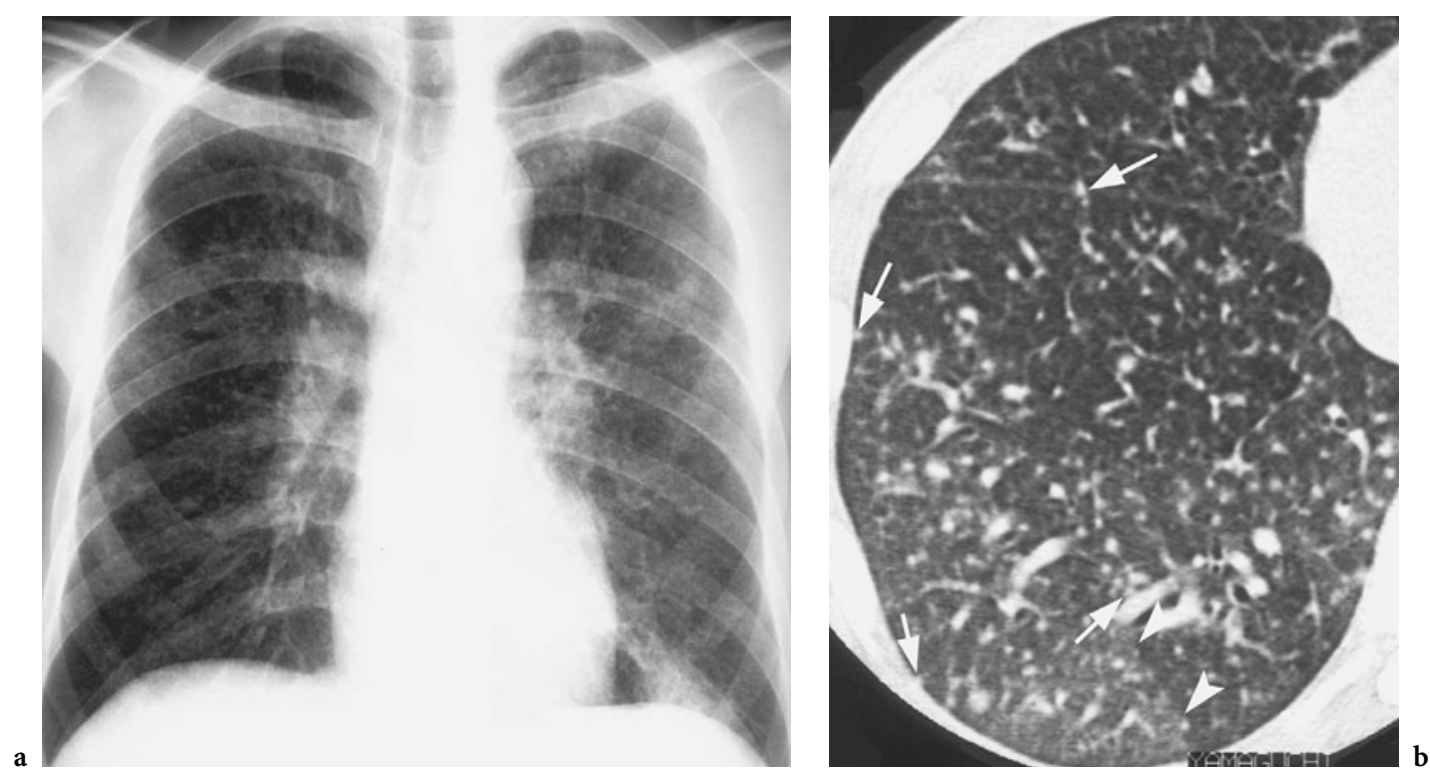

Fig. 23.9a,b. Miliary tuberculosis in a 39-year-old man with acute myelocytic leukemia. a Posteroanterior chest radiograph shows diffuse and bilateral pulmonary micronodules with focal consolidations in the left upper and lower lobes. b Axial HRCT scan shows numerous miliary nodules throughout both lungs. Some of these nodules are located on the pleural surface or on the pulmonary vessels (arrows), showing random distribution of the nodules within the secondary pulmonary lobules. Also note patchy ground-glass opacity in the right lower lobe (arrowheads), which probably shows widespread interstitial granuloma of a size below the limits of resolution on HRCT. (With permission from [TANAKA et al. 2002])

tic plugs within the respiratory bronchioles, alveolar ducts, and adjacent alveolar spaces. HRCT shows focal airspace consolidation, poorly-defined masses, or centrilobular nodules. These areas are typically peripheral or peribronchovascular in distribution. Eosinophilic pneumonia is characterized by the accumulation of eosinophils and macrophages in the alveolar spaces or thickened alveolar septa. CT is useful in demonstrating the peripheral nature of the lesions. Rossi et al. (2000) also mentioned the possibility of pulmonary hemorrhage, bronchiolitis obliterans, pulmonary edema, pulmonary hypertension, or veno-occlusive disease as pathologic features of pulmonary drug toxicity. In a report of 20 patients with drug toxicity who underwent highdose chemotherapy and autologous HSCT, PATZ et al. (1994) found scattered, predominantly peripheral ground-glass opacity and airspace consolidation in 13 patients $(65 \%)$. They speculated that a large number of alveoli, alveolar macrophages, type 2 pneumocytes, and a greater density of pulmonary arterioles within the cortical or peripheral region of the lung might be the mechanism of peripheral distribution of lesions. Perfusion differences between the cortical and medullary portions of the lung and longer peripheral blood flow transit times permit prolonged drug concentration in the cortical lung. The pathologic features of pulmonary drug toxicity are diverse, and the radiographic and CT findings are nonspecific. HRCT findings usually include airspace consolidation, ground-glass opacity and reticulation (Fig. 23.10) (TANAKA et al. 2002). Therefore, it is difficult to diagnose this entity by radiologic findings only. It must be noted that this entity is usually diagnosed by exclusion of alternative diagnoses.

\subsubsection{3}

\section{Pulmonary Hemorrhage}

This entity is associated with complicated thrombocytopenia, infectious disease or HSCT. TENHOLDER and Hooper (1980) noted that this was the most common cause of non-infectious pulmonary complications in patients with leukemia and Bodey et al. (1996) found it in $54 \%$ of 50 autopsied cases of acute leukemia. Diffuse alveolar hemorrhage is also observed in about $20 \%$ of HSCT patients (WoRTHY et al. 1997a) and occurs especially in the neutropenic phase. The clinical manifestation is acute and nonspecific; it is difficult to diagnose before death since hemoptysis is rare. The mortality rate is high, about $80 \%$. Early diagnosis followed by prompt steroid 


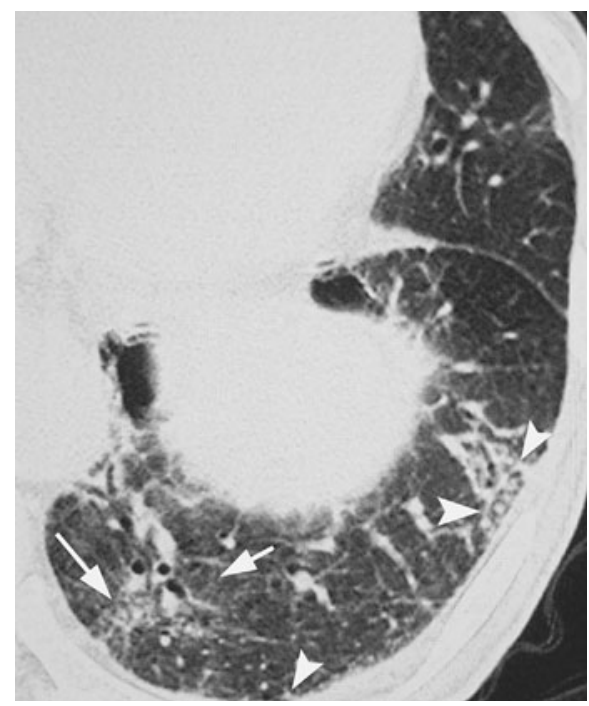

Fig. 23.10. Drug toxicity induced by phosphomycin in a 73-yearold man with chronic myelocytic leukemia. Axial HRCT scan shows patchy ground-glass opacity (arrows) and linear-reticular opacities (arrowheads) mainly in the subpleural zone.

therapy is the only way to improve the survival rate. It is important to perform bronchoalveolar lavage if this entity is suspected because bronchoalveolar lavage can show evidence of hemorrhage by revealing hemosiderin-laden macrophages. The causes of this entity are speculated to be damage to the pulmonary vasculature by GVHD, pre-transplantation chemotherapy or total body irradiation. Whether the process is a distinct entity or whether it represents a part of a spectrum of severe pulmonary edema or idiopathic pneumonia syndrome is not yet known.

The most common, but non-specific CT findings consist of widespread ground-glass opacity or consolidation (Fig. 23.11) (PrIMACK et al. 1995), within which reticulation is often recognized (crazy-paving appearance). Typically, the most peripheral lung zones or subpleural regions are spared.

\subsection{2}

\section{HSCT Specific Complications}

HSCT has made it possible to treat leukemia patients with high-dose chemotherapy and total body irradiation. After HSCT, there is a neutropenic phase, lasting 10 to 12 days with peripheral stem cells, and up to 3 weeks with bone marrow. After the neutropenic phase, an immunosuppressive state continues for about 1 year after allogeneic HSCT. This period is
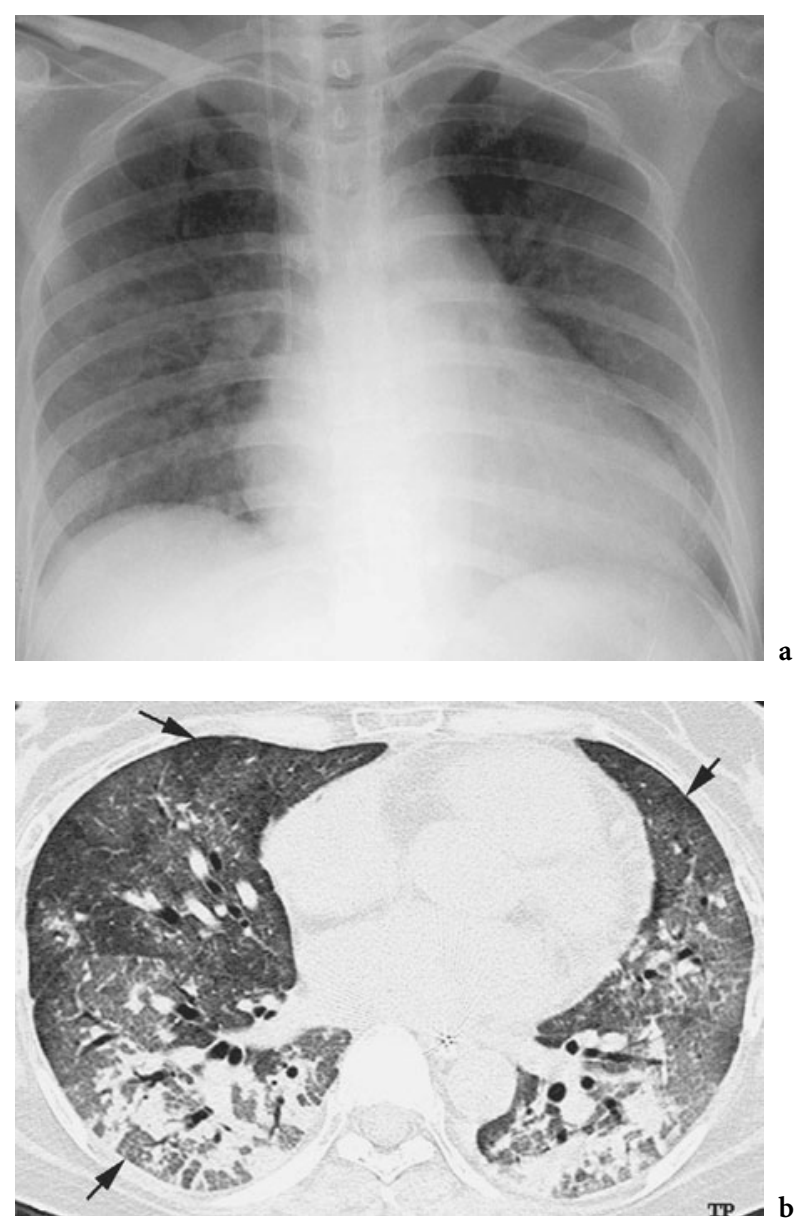

Fig. 23.11a,b. Diffuse pulmonary hemorrhage in a 37-year-old woman with acute lymphocytic leukemia. a Posteroanterior chest radiograph shows interstitial changes predominantly distributed in the bilateral lower lung zones. b Axial HRCT scan shows extensive ground-glass opacity and airspace consolidation which distribute mainly at the medullary region with the most peripheral zones less involved (arrows).

usually divided into early phase and late phase; the former, by definition, continues for 100 days after HSCT and the latter continues for one year (or more) after HSCT (Fig. 23.1) (HASLETON and DoRAN 1996). Chest complications after HSCT are a major problem and occur in 40 to $60 \%$ of such patients (KrowKA et al. 1985; Worthy et al. 1997a).

\subsubsection{1.}

\section{Infectious Conditions}

Although any infectious disorder can occur after HSCT, especially in the neutropenic or early phase, cytomegalovirus pneumonia is the most frequent. 
23.2.2.1.1

Cytomegalovirus Pneumonia

Cytomegalovirus (CMV) infection occurs in $70 \%$ of allogeneic HSCT recipients, but less than one-third develop CMV pneumonia (Worthy et al. 1997). It typically occurs in the early phase. The causes of CMV infection include reactivation of endogenous latent virus in profoundly immunosuppressed recipients, or acquisition of exogenous infection from CMV seropositive bone marrow grafts or blood products. Reported mortality rate is up to $85 \%$. Although the detection of early CMV antigen using bronchoalveolar lavage fluid may be a good method in CMV related pneumonia, it should be noted that CMV is sometimes isolated in the absence of active disease. Nowadays, the systematic search for CMV antigens in peripheral leucocytes and early treatment has dramatically decreased the incidence of CMV pneumonia and CMV-related mortality. The basic pathologic finding is an alveolar pattern consisting of alveolar macrophages, fibrin, hyaline membranes, proliferating reactive pneumocytes, and hemorrhagic exudates, consistent with diffuse alveolar damage. Interstitial thickening without airspace disease may sometimes be seen. Interstitial infiltrates consisting of lymphocytes may sometimes result in alveolar wall or interlobular septal thickening.

CMV pneumonia shows various CT findings, including patchy or widespread ground-glass opacity, air-space consolidation, nodules with the CThalo sign, and centrilobular nodules (Fig. 3.12) (Primack and Müller 1994; Webb et al. 1996; KANG et al. 1996). In a report of 21 patients with AIDS and CMV pneumonia by McGuinNess et al. (1994), ground-glass opacity or airspace consolidation were observed in 13 patients and corresponded mainly to an airspace filling process of diffuse alveolar damage. They also reported pulmonary masses and miliary patterns. Nodules with the CT-halo sign correspond to the hemorrhagic nodules. These findings are nonspecific, and it is often difficult to differentiate them from those of other entities including Pneumocystis carinii pneumonia and pulmonary hemorrhage.

\subsubsection{2}

\section{Pulmonary Edema}

Pulmonary edema is a common complication in the neutropenic phase although the exact incidence is not known. The onset is usually rapid and occurs in the second or third week post transplantation. The causes of this entity are thought to be acute GVHD, cardiac

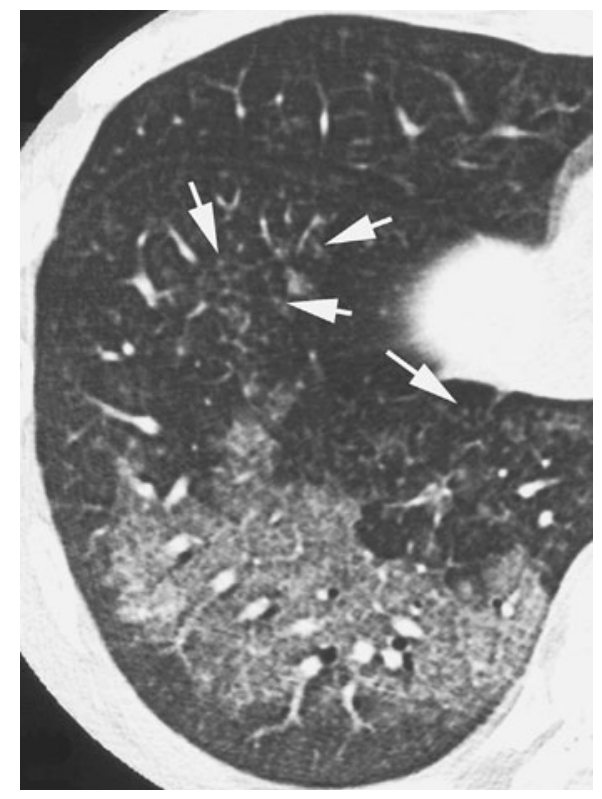

Fig. 23.12. Cytomegalovirus pneumonia in a 35-year-old man with acute myelocytic leukemia. Axial HRCT scan shows extensive ground-glass opacity in the right lower lobe. Note that centrilobular nodules can be seen (arrows). It is quite difficult to differentiate this finding from Pneumocystis carinii pneumonia.

or renal impairment induced by intensive chemotherapy, the increased permeability of pulmonary vessels induced by total body irradiation, sepsis, cyclosporine $\mathrm{A}$, prophylactic granulocyte transfusions and the infusion of large volumes of fluid to administer drugs (Hasleton and Doran 1996; Worthy et al. 1997a). Cardiac dysfunction may be caused by adriamycin, cyclophosphamide or radiation therapy.

Chest radiographic findings include diffusely increased interstitial markings such as Kerley A, $\mathrm{B}$ and $\mathrm{C}$ lines, peribronchial cuffing, hilar haze, ground-glass appearance and vascular redistribution. Characteristic CT findings include enlargement of pulmonary vessels, ground-glass opacity or air-space consolidation in the hilar or peribronchial regions, thickening of interlobular septa and pleural effusion (Fig. 23.13) (PRIMACK and MÜLler 1994; Worthy et al. 1997a).

\subsubsection{3}

\section{Idiopathic Pneumonia Syndrome}

This entity is an early phase complication and occurs in approximately $12 \%$ of allogeneic HSCT patients. It is defined as diffuse lung injury occurring after HSCT for which an infectious etiology is not identified (CLARK et 


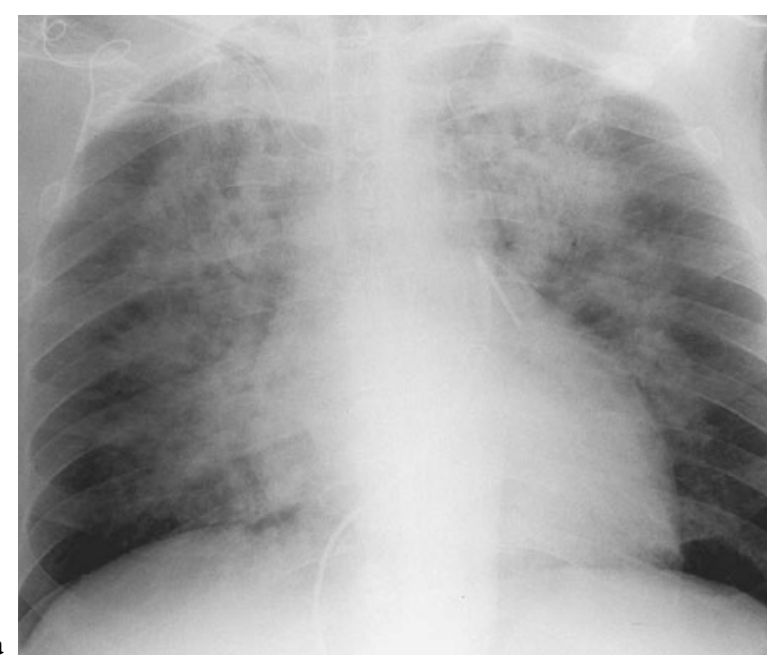

b

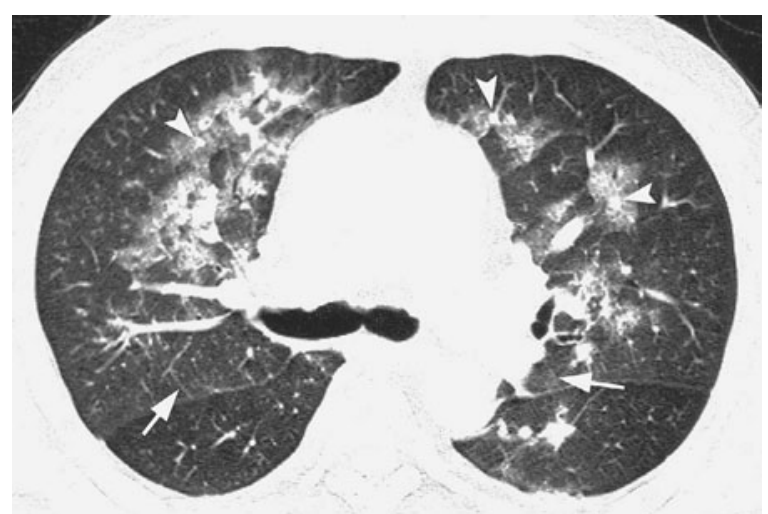

Fig. 23.13a,b. Pulmonary edema in a 58-year-old man with multiple myeloma. a Posteroanterior chest radiograph shows extensive airspace consolidation with air bronchogram distributed mainly in the bilateral hilar regions. Note an associated cardiomegaly. b Axial HRCT scan shows ground-glass opacity and airspace consolidation distributed along the bronchovascular bundles. Thickening of interlobular septa is seen (arrows). Note that the pulmonary arteries became greater in diameter (arrowheads) than accompanying bronchi.

al. 1993). It is probably caused by toxicity from the pretransplantation chemotherapy and total body irradiation (ClARK et al. 1993; WorTHy et al. 1997a; KrowKA et al. 1985). Mortality rate approaches $80 \%$.

The pathologic feature of idiopathic pneumonia syndrome is diffuse alveolar damage with an interstitial mononuclear cellular infiltrate. Clinically, diffuse alveolar damage is seen in acute interstitial pneumonia or acute respiratory distress syndrome (ARDS). Although it is not clear if idiopathic pneumonia syndrome is the same entity as acute interstitial pneumonia or ARDS, the pathologic feature is the same among these 3 entities. Diffuse alveolar damage is manifested by injury to the alveolar lining and endothelial cells, pulmonary edema, hyaline membrane formation, and extensive fibroblastic proliferation but little mature collagen deposition. The pathologic appearance of diffuse alveolar damage can be separated into acute exudative, subacute proliferative and chronic fibrotic phases.

HRCT findings of diffuse alveolar damage, focal or diffuse ground-glass opacity were seen in all reported cases. Air-space consolidation is slightly less common, but seen in most cases. Usually, groundglass opacity and airspace consolidation are denser in attenuation in the dependent lung zone than in the non-dependent lung (Fig. 23.14). ICHIKADo et al. (1997) and PrimACK et al. (1993) observed areas of ground-glass opacity with focally spared regions that
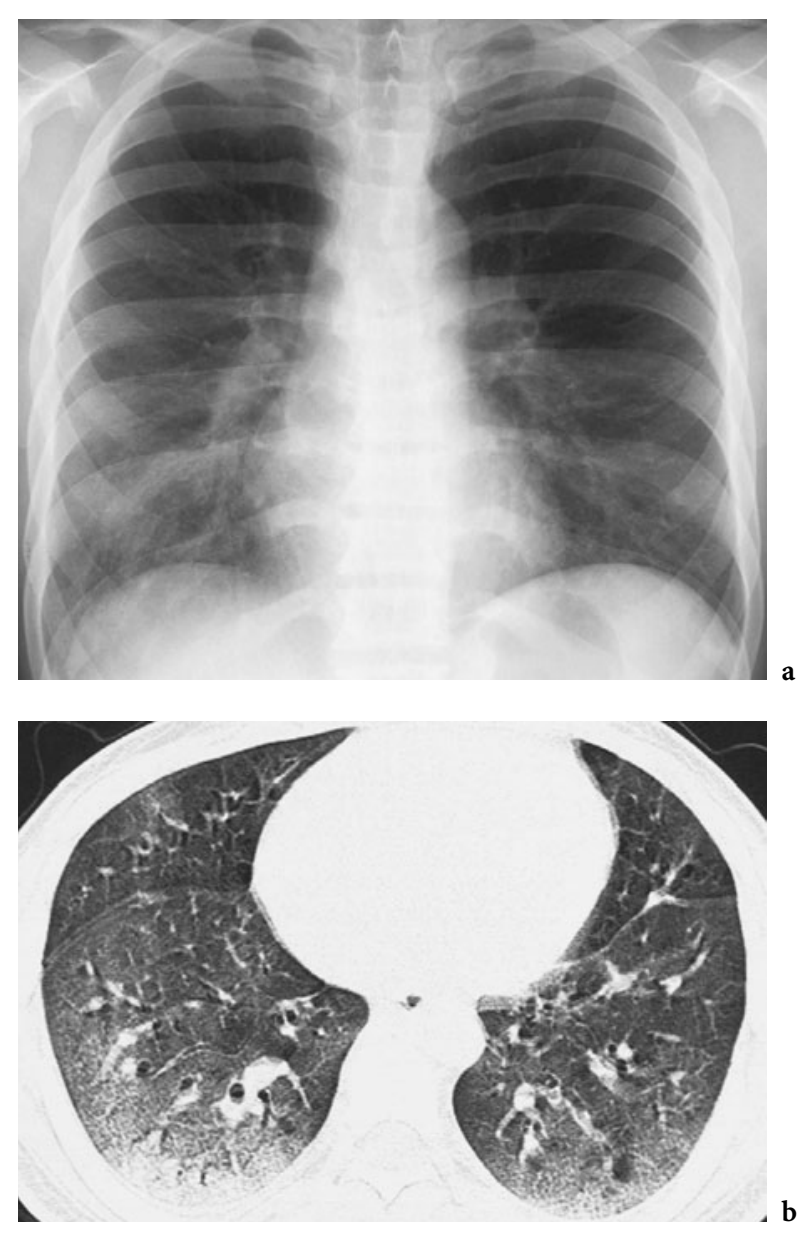

Fig. 23.14a,b. Idiopathic pneumonia syndrome in a 27-yearold man with acute myelocytic leukemia. a Posteroanterior chest radiograph shows bilateral mixed interstitial and alveolar opacities. b Axial HRCT scan shows widespread groundglass opacity distributed in the bilateral lung field, especially in the dependent lung area, creating a density gradient. Autopsied specimens of this patient showed diffuse alveolar damage. (With permission from [TANAKA et al. 2002]) 
produced a geographic appearance. In this respect, it might be difficult to distinguish idiopathic pneumonia syndrome from Pneumocystis carinii pneumonia. However, a density gradient towards the dependent lung zone may be the key finding of this entity. Traction bronchiectasis and architectural distortion are relatively common findings and probably indicate the proliferative or fibrotic phase. The presence of honeycombing is indicative of the fibrotic phase. It is essentially a diagnosis of exclusion because HRCT findings are non-specific.

\subsubsection{4}

\section{Bronchiolitis Obliterans}

Bronchiolitis obliterans is a late phase complication and occurs in approximately $10 \%$ of patients who develop chronic GVHD. Most patients receive an allogeneic HSCT for aplastic anemia or leukemia. It rarely occurs in patients who undergo autologous HSCT. The cause is uncertain, however, it is speculated to be direct damage to the small airways induced by chronic GVHD (HASLETON and DoRAN 1996). Risk factors include immunosuppression with methotrexate, pre-HSCT chemotherapy, irradiation, and low serum immunoglobulins after HSCT. This complication usually occurs 6 months after transplantation, with a range of 2-20 months. The mortality rate is high, and the value of treatment is questionable. The pathologic finding of bronchiolitis obliterans is constrictive bronchiolitis; submucosal and peribronchiolar fibrosis, usually irreversible, is present, resulting in extrinsic narrowing and obliteration of the lumen of small bronchi and bronchioles. In the early stages of disease, there is probably a cellular inflammatory and fibroblastic reaction in the bronchiole, but the more typical finding is fibrosis with little active inflammation.

Chest radiography shows hyperinflation with or without focal or diffuse opacities. The diagnosis is based on the clinical findings and the results of pulmonary function tests. Although it can be confirmed histologically by surgical lung biopsy specimen, this is not always necessary. It is possible to diagnose this entity by using the characteristic HRCT findings and the evidence of airflow obstruction shown by pulmonary function tests. HRCT including expiratory technique is essential for the correct diagnosis of this entity. Common HRCT findings consist of patchy or diffuse areas of air trapping (Fig. 23.15), mosaic perfusion, and bronchial dilatation. Centrilobular nodules are sometimes seen. Mosaic perfusion is defined as marked heterogeneity of lung attenuation,
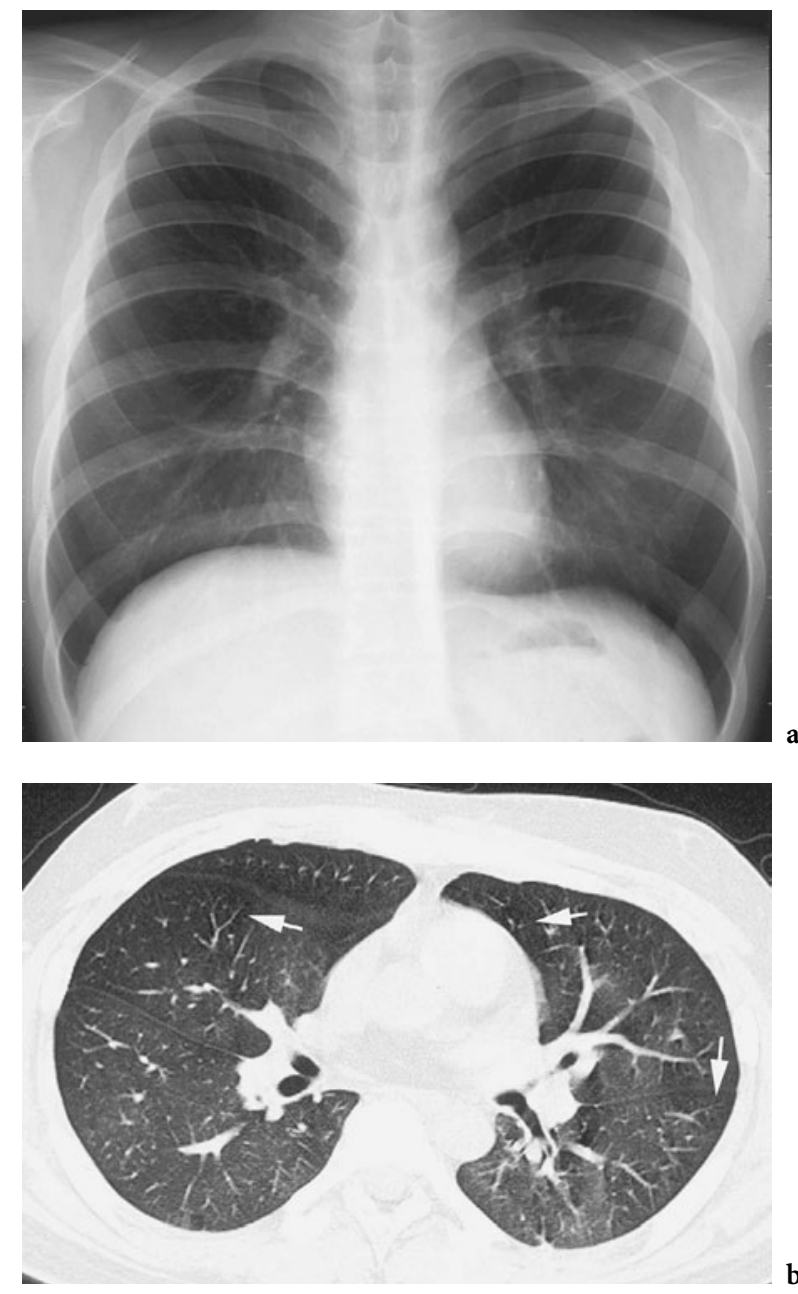

Fig. 23.15. Bronchiolitis obliterans in a 15-year-old boy with acute myelocytic leukemia. a Posteroanterior chest radiograph shows no abnormal finding except for minimal hyperinflation, which was not previously visible. b Expiratory axial thin-section CT scan shows multiple patchy air trapping (arrows).

with lobules of increased and decreased lung density that create a striking patchwork pattern. The areas of decreased lung density are presumed to show air trapping, with associated pulmonary oligemia. The areas of increased lung density may be due to redistribution of blood flow to more normal areas of the lung. The pulmonary vessels within the decreased lung attenuation regions may appear smaller in caliber.

Mosaic perfusion is frequently seen in several reports, however, in LAU et al. (1998) study, this finding is not so specific for bronchiolitis obliterans because the control group with normal pulmonary function could represent this finding. In their study, 
the specificity was $60 \%$. Bronchial dilatation and air trapping are thought to be more reliable findings. In a study by WORTHY et al. (1997b) of 15 patients with bronchiolitis obliterans, the sensitivity of bronchial dilatation and air trapping was $80 \%$ for both, and the specificity of bronchial dilatation and air trapping was $78 \%$ and $94 \%$, respectively. The combination of bronchial dilatation and air trapping was seen only in patients with bronchiolitis obliterans, in their study. It should be stressed that expiratory CT is needed if bronchiolitis obliterans is suspected in HSCT patients.

\subsubsection{5}

\section{Bronchiolitis Obliterans Organizing Pneumonia}

Bronchiolitis obliterans organizing pneumonia (BOOP) is also a well-recognized late phase complication in HSCT patients. The incidence rate is uncertain. BOOP is characterized pathologically by edematous granulation tissue polyps in the lumina of alveolar ducts and bronchioles in association with a variable degree of interstitial and airspace infiltration by mononuclear cells and foamy macrophages, which can be followed by fibroblast proliferation and collagen deposition. The peribronchial distribution of these changes is a clue to the pathologic diagnosis of BOOP. BOOP is a common pathologic pattern of lung injury, occurring in a variety of diseases. Because of the patchy nature of BOOP, surgical biopsy may be required if transbronchial biopsy is nondiagnostic.

Typical and characteristic CT findings are patchy ground-glass opacity or air-space consolidation often distributed at the peribronchial and subpleural regions (Fig. 23.16). In a study by PreIDLER et al. (1996), all 15 patients showed circumscribed areas of airspace consolidation, almost identical to large nodules. The areas of airspace consolidation were almost always multifocal, and in 14 patients the areas were bilateral and non-segmental, and usually distributed at the lung periphery, and showing lower lung predominance. Although consolidation is more commonly observed in immunocompetent patients, ground-glass opacity or nodules are more frequently observed in immunocompromised patients. Ground-glass opacity, usually random in distribution, is seen in $60 \%$ of cases. Nodules are seen in $30 \%$ of cases. Centrilobular nodules with branching linear structures mimicking cellular bronchiolitis have been reported. In a study of 8 patients, air-space consolidation and ground-glass opacity were sharply demarcated from each other and from normal lung,
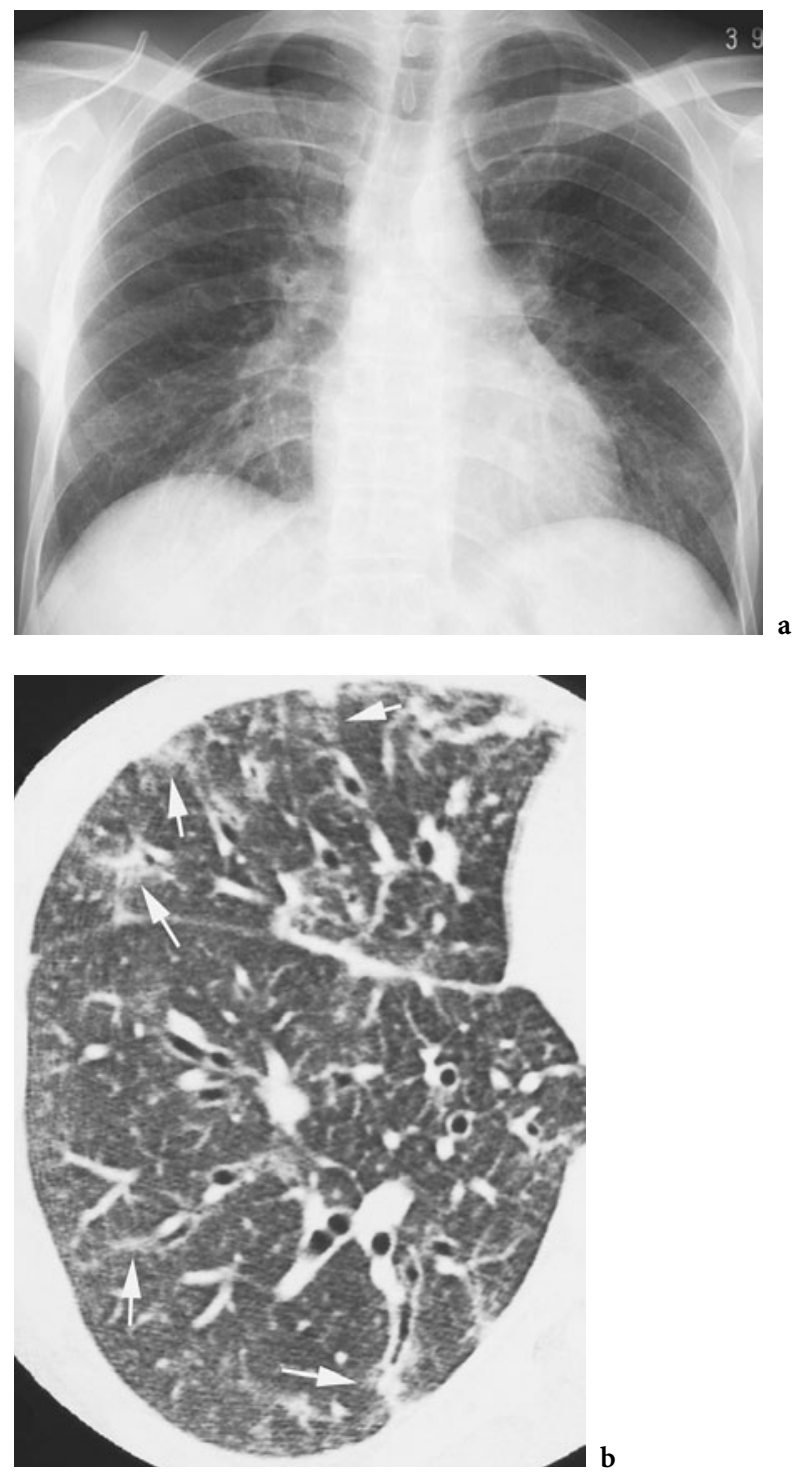

Fig. 23.16. Bronchiolitis obliterans organizing pneumonia in a 36-year-old man with chronic myelocytic leukemia. a Posteroanterior chest radiograph shows minimal patchy subpleural airspace disease. b Axial HRCT scan shows extensive ground-glass opacity and airspace consolidation, which predominantly distribute along the bronchovascular bundles and/or subpleural zones (arrows). (With permission from [TANAKA et al. 2002])

exhibiting panlobular or geographic distribution. In that study, air-space consolidation corresponded mostly to organizing pneumonia and ground-glass opacity corresponded to alveolar septal inflammation and alveolar cellular desquamation with a little granulation tissue in the terminal air space (Nishimura and IтоH 1992). 


\section{3}

\section{Post Radiation Changes}

Patients with intrathoracic lymphoma receive radiation therapy as part of their treatment, or in combination with chemotherapy (BRADY and LEVITT 1998). For these patients, the battle is often won or lost in the thorax. The mantle field used for definitive radiation therapy in patients with Hodgkin or non-Hodgkin lymphomas includes all the major lymph node regions above the diaphragm. The field extends from the inferior portion of the mandible nearly to the level of the insertion of the diaphragm. Lung blocks are designed to conform to patient anatomy and tumor distribution. After radiation therapy, a variety of changes may occur in the thorax. Most patients remain asymptomatic with generally subclinical manifestations of radiationrelated changes. Indeed, in recent years, thanks to new modalities of irradiation (decreased intensity, replacement of "mantle field" by "involved field", hyperfractionated irradiation, etc) the frequency of radiation-induced complications has decreased. However, as the number of survivors increases, several late effects of treatment are becoming evident (Table 23.1) (Mesurolle et al. 2000).

\subsection{1}

Lung Injuries

\subsubsection{1}

\section{Radiation Pneumonitis and Fibrosis}

Post radiation therapy effects in the lungs are divided into early and late stages (LiBshitz 1993; LiBshitz and Shuman 1984; IKezoe et al. 1988).

The early stage - radiation pneumonitis - occurs usually about 8-12 weeks after completion of radiation therapy but can occur earlier or much later. It consists of cellular infiltration that is predominantly composed of macrophages. Radiation pneumonitis varies from minimal to extremely marked changes in the paramediastinal areas and in both apices (Libshitz et al. 1973). In case of splenic irradiation (rarely used now), radiation pneumonitis can occur in the left lung base. Radiologically, there is a diffuse haze in the irradiated region with obscuring of vascular outlines (Fig. 23.17). Patchy consolidations appear and then coalesce to form a relatively sharp edge that conforms to treatment portals rather than to anatomic boundaries (Fig. 23.18). CT may reveal radiation changes when the chest X-ray is normal (Fig. 23.19) (IKEzoE et al. 1988). Occasionally, a pleu-

Table 23.1. Post-radiation thoracic injuries. (Modified with permission from [Mesurolle et al. 2000])

\begin{tabular}{|c|c|c|c|c|}
\hline Target Organ & Complication & Time to Onset & Fractionated Dose & Refs \\
\hline \multirow[t]{2}{*}{ Lung } & Pneumonitis & 8-12 weeks (acute), 6-24 months (late) & $30 \mathrm{~Gy}$ & $\begin{array}{l}\text { Mosvas et al. } \\
\text { (1997) }\end{array}$ \\
\hline & Pneumothorax & 16 months & $>30 \mathrm{~Gy}$ & $\begin{array}{l}\text { Penniment and } \\
\text { O’Brien (1994) }\end{array}$ \\
\hline Lymph nodes & Calcifications & $>12$ months & $\begin{array}{l}\text { No minimal } \\
\text { dose defined }\end{array}$ & $\begin{array}{l}\text { BERETON and } \\
\text { Johnson } 1974\end{array}$ \\
\hline Esophagus & Stricture & 3-18 months & 60 Gy & $\begin{array}{l}\text { LEPKE and LIB- } \\
\text { SHITZ (1983) }\end{array}$ \\
\hline Vascular tree & $\begin{array}{l}\text { Stenosis } \\
\text { Occlusion } \\
\text { Pseudoaneurysm }\end{array}$ & $10-15$ years & $\begin{array}{l}\text { Aorta and pulmonary } \\
\text { artery, 24-44 Gy; sub- } \\
\text { clavian artery, 40-60 } \\
\text { Gy }\end{array}$ & $\begin{array}{l}\text { FAJARDO and } \\
\text { BERTHRONG } \\
(1983)\end{array}$ \\
\hline \multirow[t]{3}{*}{ Heart } & $\begin{array}{l}\text { Coronary artery } \\
\text { disease }\end{array}$ & $10-15$ years & $\begin{array}{l}>30 \mathrm{~Gy} \\
\text { before } 20 \text { years of age }\end{array}$ & $\begin{array}{l}\text { Kopelson and } \\
\text { Herwig (1978) }\end{array}$ \\
\hline & $\begin{array}{l}\text { Pericarditis } \\
\text { (3 types) }\end{array}$ & $\begin{array}{l}\text { 1. During radiation therapy } \\
\text { (associated with chemotherapy) } \\
\text { 2. Post-therapy, acute effusion } 12-18 \text { months } \\
\text { 3. Post-therapy, chronic effusion, } 48 \text { months }\end{array}$ & $40 \mathrm{~Gy}$ & $\begin{array}{l}\text { APPLEFELD et al. } \\
(1981)\end{array}$ \\
\hline & $\begin{array}{l}\text { Conduction } \\
\text { abnormalities }\end{array}$ & 10 years & $40 \mathrm{~Gy}$ & $\begin{array}{l}\text { CoHen et al. } \\
(1981)\end{array}$ \\
\hline \multirow[t]{2}{*}{ Malignancy } & Breast carcinoma & $15-19$ years & $\begin{array}{l}>20 \mathrm{~Gy} \\
\text { before } 35 \text { years of age }\end{array}$ & $\begin{array}{l}\text { Bнatia et al. } \\
\text { (1996) }\end{array}$ \\
\hline & Sarcoma & $>5$ years & $\begin{array}{l}\text { No minimal dose } \\
\text { defined }\end{array}$ & LIBSHITZ (1994) \\
\hline
\end{tabular}




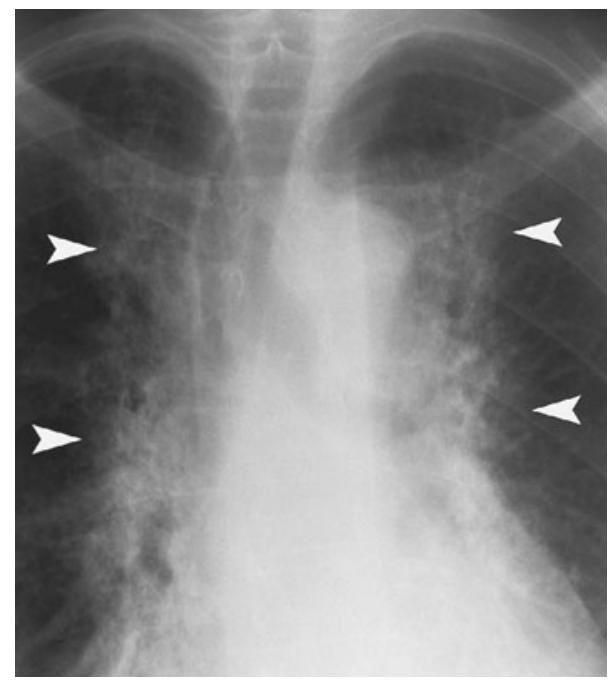

Fig. 23.17. Radiation pneumonitis in a 52-year-old man after radiation therapy for Hodgkin disease. Posteroanterior chest radiograph performed two months after completion of radiation therapy shows typical moderate post-radiation pneumonitis with paramediastinal consolidations (arrowheads) obscuring vascular outlines.

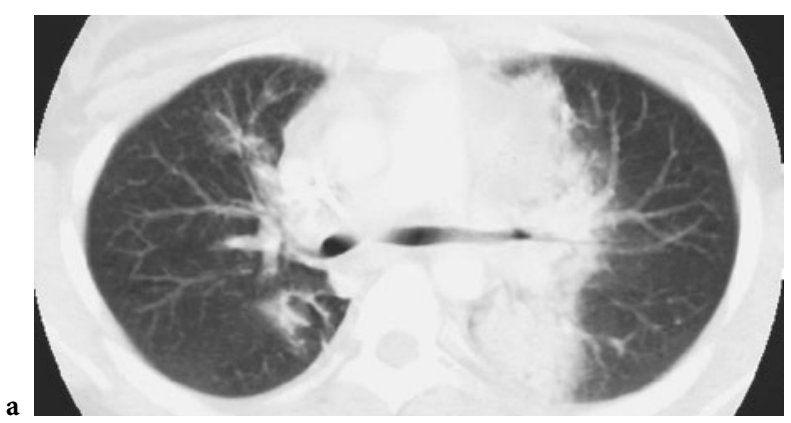

b

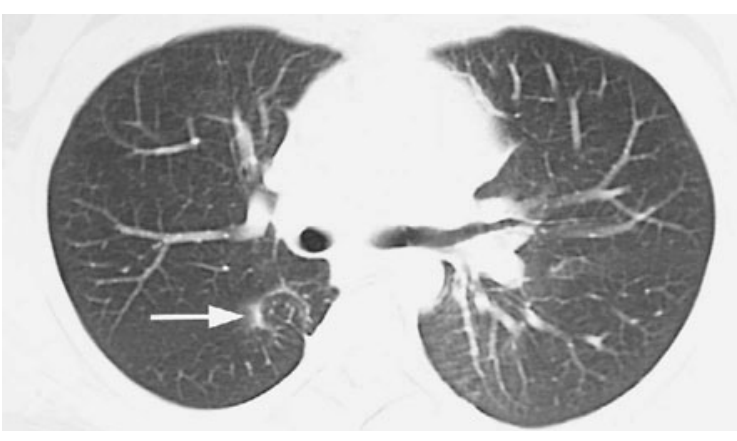

Fig. 23.18a,b. Radiation pneumonitis in a 38-year-old woman after radiation therapy for Hodgkin disease a Axial CT scan performed two months after completion of radiation therapy shows paramediastinal dense consolidation confined to the radiation ports. b Axial CT scan performed eighteen months after completion of irradiation shows no significant injury detected except for slight linear infiltrate (early stage of fibrosis) (arrow).

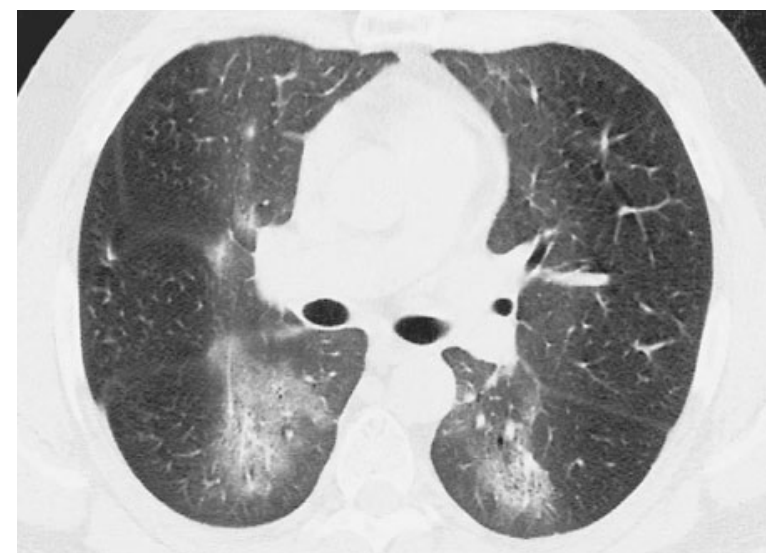

Fig. 23.19. Radiation pneumonitis in a 42-year-old man after radiation therapy for Hodgkin disease. Axial HRCT scan shows mild paramediastinal alveolar and ground glass opacities confined in the radiation port.

ral effusion develops on the irradiated site. Typically, this effusion is small and is seen with acute radiation pneumonitis (LiBshitZ 1993).

The late stage is secondary to incompletely resolved radiation pneumonitis. Fibrous changes take 6-24 months to evolve but remain stable after 2 years (LogAN 1998). These changes are marked by collagen deposition and fibrosis. Volume loss causes coalescence of any linear infiltrates that were present. The borders of the fibrotic area become straight, conforming to the radiation port. Pleural thickening develops in lung apices, and the hilar structures are superomedially retracted (Fig. 23.20). In case of severe changes, marked retraction can induce a narrowing of the cardiomediastinal silhouette (LOYER et al. 2000). CT scans may reveal well-defined areas of atelectasis with parenchymal distortion and traction bronchiectases. These changes are variably present after 30-40 Gy, and universally seen after more than $40 \mathrm{~Gy}$. In hematologic patients, the maximum dose is $40 \mathrm{~Gy}$ (Mosvas et al. 1997). Many factors can alter the risk of developing radiation-related pulmonary damage. These include (a) prior irradiation; (b) chemotherapy (doxorubicin, actinomycin D, busulfan, bleomycin, methotrexate and interferon); (c) a larger target volume, a higher total radiation dose and daily fraction size, and a shorter overall treatment time; and (d) withdrawal of steroid therapy. In addition, radiation to the chest, even when limited to the mediastinum, has been associated with an increased risk of bleomycin-induced pulmonary toxicity (BRICE et al. 1991). The lung target volume irradiated may be the most important factor (RUBIN 

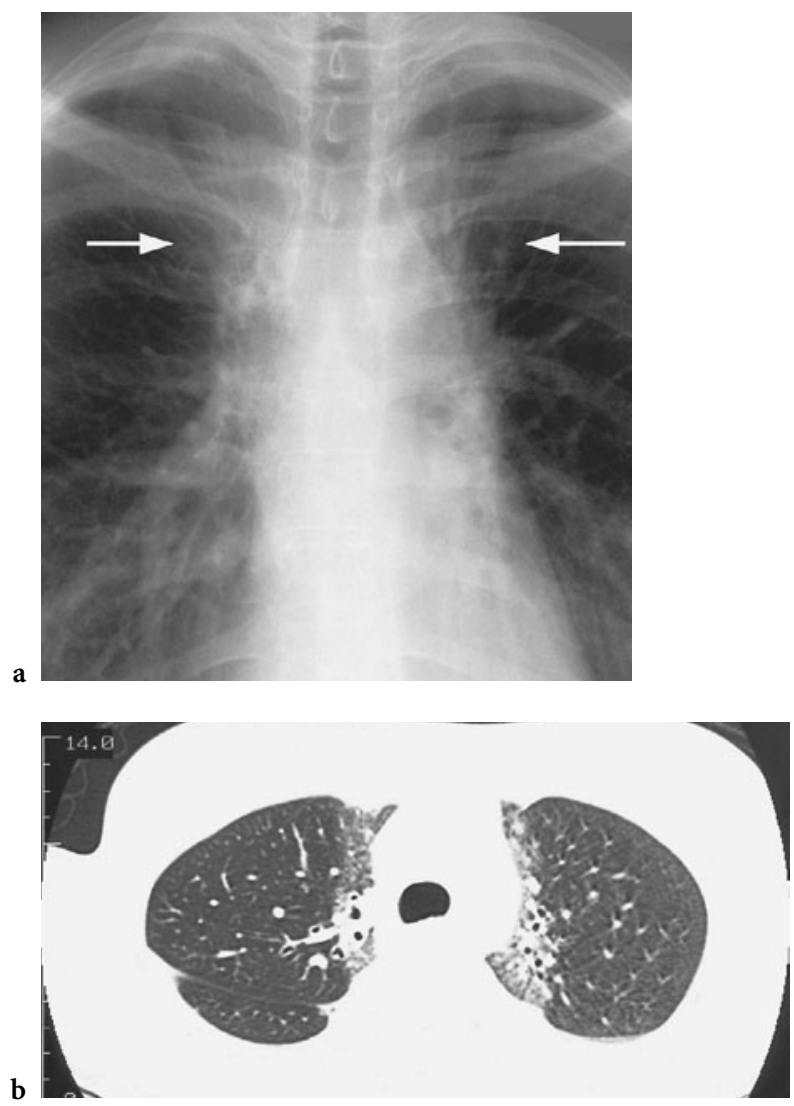

Fig. 23.20a,b. Radiation fibrosis in a 39-year-old woman after radiation therapy for Hodgkin disease. a Posteroanterior close-up view chest radiograph demonstrates superomedially retraction of hilar structures associated with moderate postradiation paramediastinal fibrosis (arrows). b Axial HRCT scan shows paramediastinal post radiation fibrosis confined to the radiation port. Note traction bronchiectasis, ground glass opacity and sharp demarcation between normal and irradiated lung. These lesions are related to subacute radiation changes.

and CASARETT 1998). A reduction of at least $15-20 \%$ of the total dose has been recommended when chemotherapy is administered concurrently (Roswit and White 1977) especially with bleomycin, platins or gemcitabine.

\subsubsection{2}

\section{Spontaneous Pneumothorax}

Treatment-related pneumothorax has occasionally been reported in patients who received radiation therapy for a primary malignancy (Rowinsky et al. 1985). Pezner et al. (1990) reported a frequency of spontaneous pneumothorax of $2 \%$ in patients with Hodgkin disease who were treated with mantle radia- tion therapy. The patients reported in the literature received more than $30 \mathrm{~Gy}$ of radiation (PENNIMENT and O'BRIEN 1994). Pneumothorax can be recurrent, is rarely bilateral, and occurs 1 to 31 months after radiation therapy, with a mean time to onset of 16 months. It usually occurs in patients with radiologic evidence of post-irradiation fibrosis. The volume is usually minimal to moderate, and most cases will reexpand without treatment (Rowinsky et al. 1985).

\subsection{2}

\section{Mediastinal Changes}

\subsubsection{1 \\ Thymic Cysts}

Thymic cysts may arise in patients who have undergone irradiation for Hodgkin disease. These cysts are thought to occur either secondarily to treatment of Hodgkin disease of the thymus or exclusively as a result of radiation effects on the thymus (KATZ et al. 1977). They manifest as a stable or progressively enlarging cyst with or without calcified parietal wall (Fig. 23.21) (BARoN et al. 1981). The CT and MR imaging appearance is the same as that of a benign cyst. Irregular or thick-walled cysts should be regarded with suspicion and may necessitate biopsy.

\subsubsection{2 \\ Calcified Lymph Nodes}

Calcifications can arise in lymph nodes after radiation therapy for lymphoma. In Hodgkin disease, calcification of a nonenlarged mass after radiation therapy signifies a favorable response to therapy (KATZ et al. 1977; Rivero et al. 1984). Calcification generally begins about 1 year after treatment and may become increasingly dense over the years (Fig. 23.22) (BERETON and Johnson 1974). Awareness of this condition allows one to avoid confusion with the changes that typify granulomatous infection.

\subsubsection{3}

\section{Benign Esophageal Injuries}

Esophageal dysmotility occurs 4-12 weeks after radiation therapy (LEPKE and Libshitz 1983). Strictures are uncommon but may occur 3-18 months after radiation therapy with a median interval of 6 months. They are usually smooth with tapered margins (Fig. 23.23) but may also have an irregular 
a
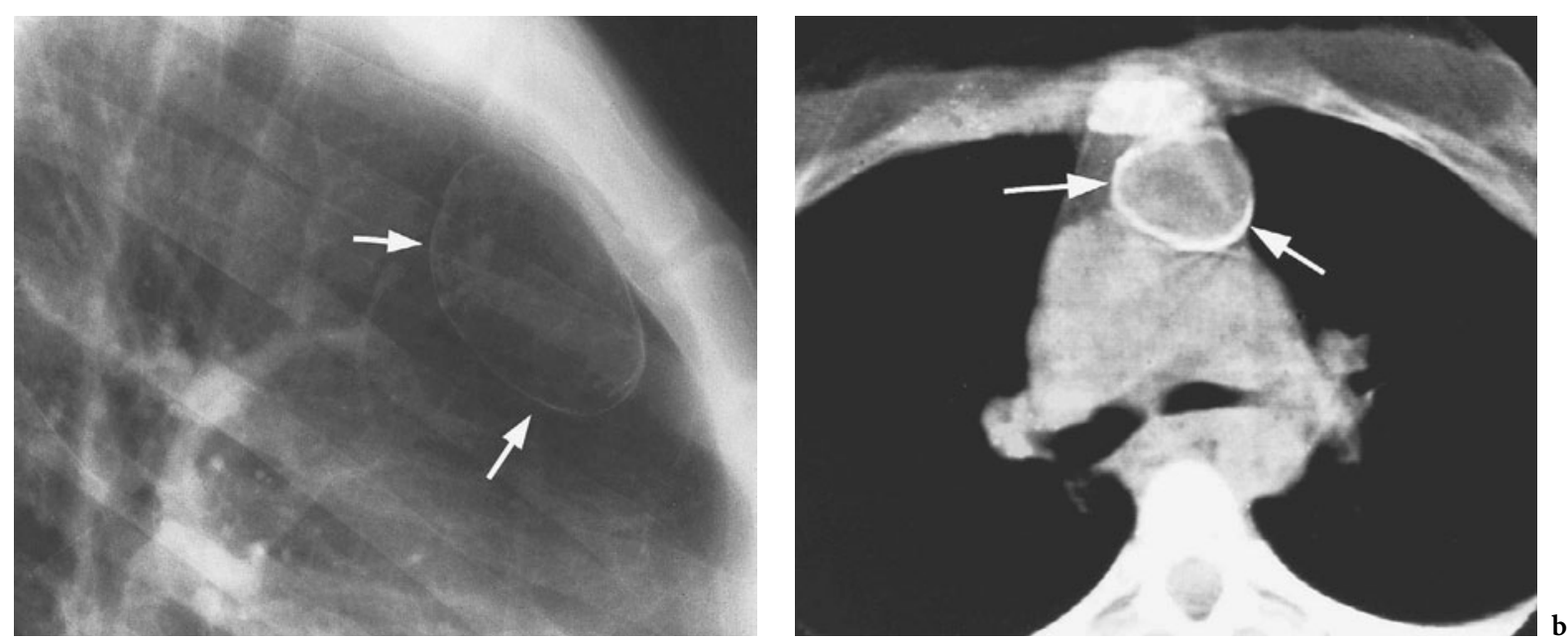

Fig. 23.21a,b. Thymic cyst in a 35-year-old man 10 years after radiation therapy for Hodgkin disease. a Lateral chest radiograph shows an ovoid, well defined lesion with a calcified parietal wall located anteriorly in the mediastinum (arrows). b Axial CT scan shows a thymic cyst with parietal wall calcifications (arrows).
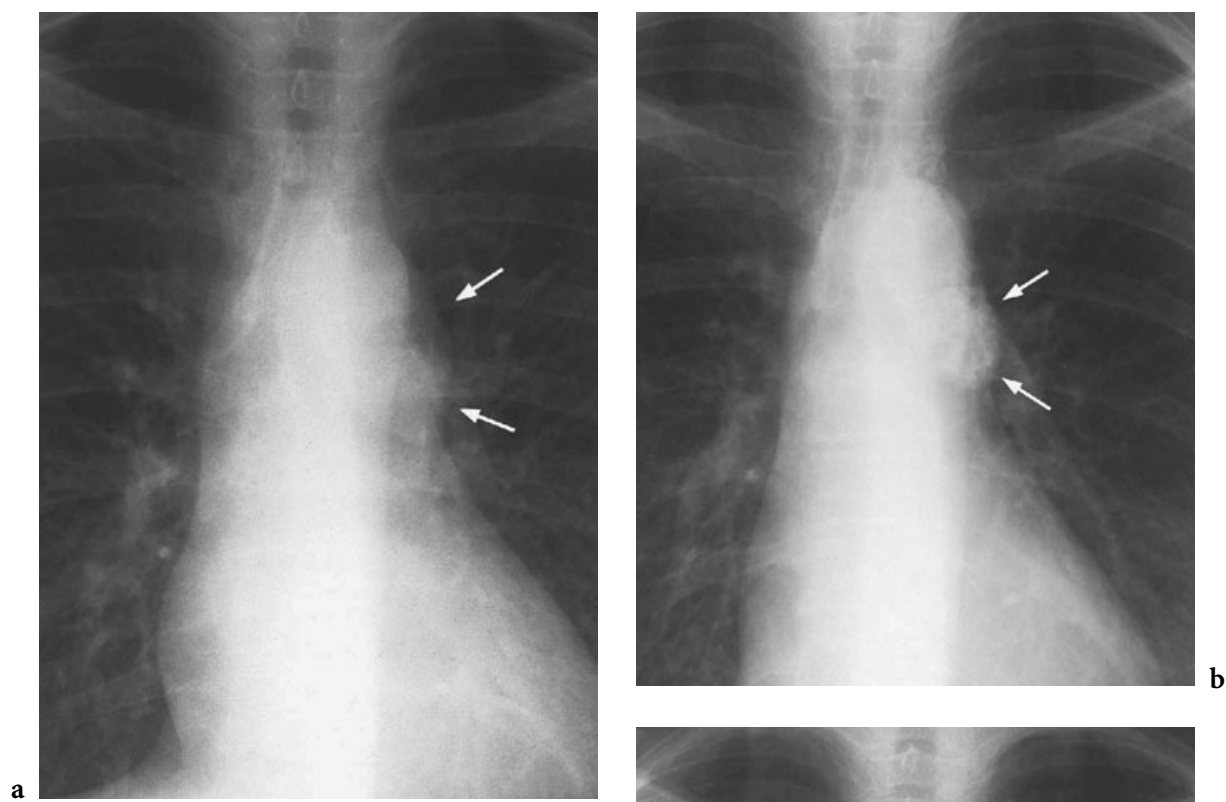

Fig. 23.22a-c. Lymph node calcifications in a 70-year-old woman after mediastinal irradiation for non-Hodgkin lymphoma. a Posteroanterior chest radiograph obtained before radiation therapy shows a lymphadenopathy located in the aortopulmonary window (arrows). Posteroanterior chest radiographs obtained (b) thirteen years and (c) twenty-eight years after radiation therapy show mediastinal lymph node calcification in the radiation field (arrows). The calcification increased in density over the years.

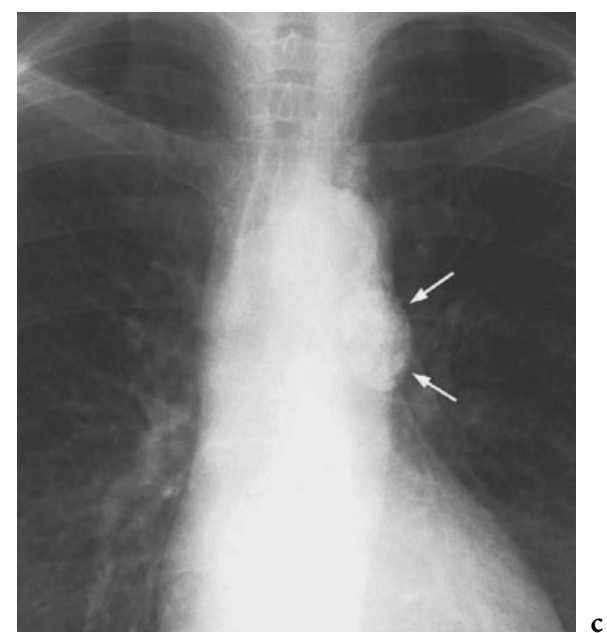




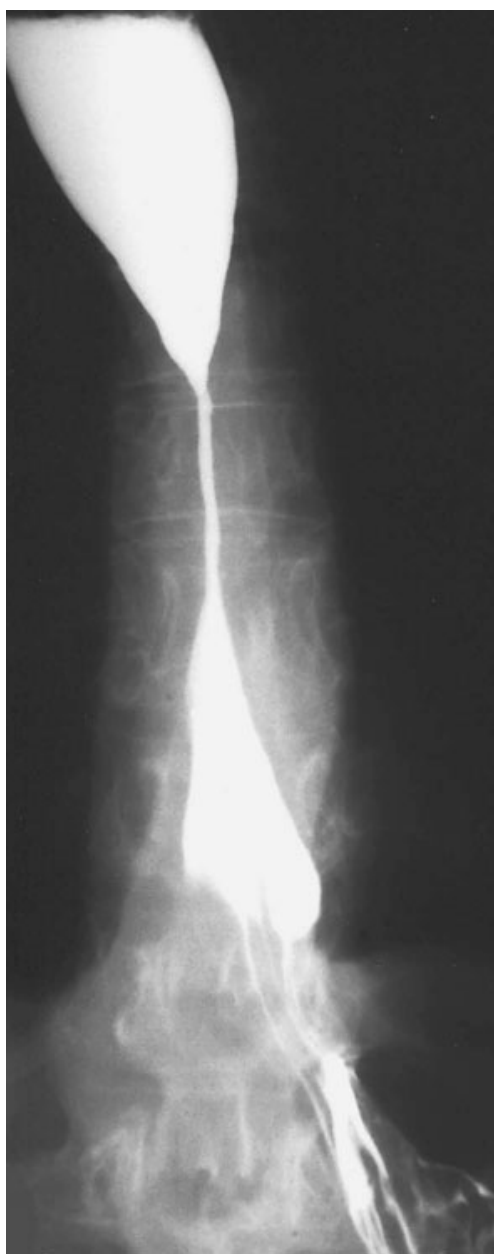

Fig. 23.23. Post radiation esophageal stricture in a 50-yearold woman one and half years after completion of radiation therapy for Hodgkin disease. Barium esophagogram shows marked smooth concentric narrowing of the lower third of the esophagus.

surface. A total dose of $50 \mathrm{~Gy}$ or more can lead to stricture formation. The prevalence of symptomatic benign strictures is probably under $2 \%$ at doses of 50 Gy or less and may rise to approximately $15 \%$ in patients treated with 60 Gy (CoIA et al. 1995). However, esophageal strictures can occur even with lowdose radiation therapy when chemotherapy (doxorubicin) is administered (LEPKE and LIBSHITZ 1983).

\subsection{3}

\section{Cardiovascular Injuries}

Cardiovascular complications of radiation therapy are often delayed and insidious. The majority of these complications has been reported in patients previously treated for Hodgkin disease. They are reported to contribute significantly to mortality in long-term survivors of Hodgkin disease, ranking behind only second malignancies and Hodgkin disease itself (LEE et al. 2000; STEWART et al. 1995). The absolute risk of cardiac-related deaths in survivors of Hodgkin disease is estimated between 9.3 and 28 per 10,000 patient years, 2 to 3 times the population risk (AISENBERg 1999; HANCOCK et al. 1993). This risk is higher in younger patients, in patients who received mediastinal doses exceeding 30 Gy (HANCOCK et al. 1993) and in those receiving additive chemotherapy (predominantly MOPP in Hodgkin disease) (GIRINSKY et al. 2000). Such radiation therapy techniques as use of a cobalt beam, preferential weighting of the anterior field, and large daily fractions have been implicated in the development of late cardiac toxic effects (VLACHAKI et al. 1998).

\subsubsection{1 \\ Vascular Injuries}

Radiation-induced vasculopathy usually occurs after about 10 years. Radiation injuries within the vascular tree most often affect the capillaries, sinusoids, small arteries, veins, and large arteries (FAJARDO and BERTHRONG 1983). When major damage (e.g., thrombosis or rupture) is sustained by an elastic artery, the damage tends to be clinically significant (STEIN and JACOBSON 1993; BENSON 1973). The only differentiating feature from radiation arteritis is that radiationinduced vasculopathy is limited to the radiation field. Stenoses and occlusions are more frequently reported than are perforations and pseudoaneurysms (FAJARDO and LEE 1975). Mediastinal fibrosis produces obliteration of normal fat planes and anatomic landmarks, which is responsible for distortion and stricture of normal vessels (QANADLI et al. 1999).

\subsubsection{2}

\section{Coronary Artery Disease}

The effect of radiation on the coronary arteries continues to fuel debate. Coronary artery stenosis occurs after radiation therapy to the mediastinum, which is usually given for Hodgkin disease. Although some studies indicate that the overall risk of a serious ischemic event in the coronary arteries is not increased in patients who received radiation therapy (BoIvin and HUTCHISON 1982), more convincing are the reports of young patients with severe coronary artery disease in whom previous irradiation is the 
only feasible explanation for the development of premature coronary artery stenosis (KopELSON and Herwig 1978; Totterman et al. 1983). Among survivors of Hodgkin disease, two studies found a threefold higher relative risk for coronary artery disease (Cosset et al. 1991; Boivin et al. 1992).

Stenosis generally affects the proximal portions of the coronary arteries (Fig. 23.24) (REINDERs et al. 1999). These sites are rarely stenotic in patients who were not treated with radiation therapy, but frequently are stenotic in patients who received radiation therapy to the mediastinum. Post-mortem examinations of young adults treated with radiation therapy for Hodgkin disease have shown marked atherosclerotic disease at the ostia and proximal courses of the coronary arteries, which correspond to the anatomic area exposed to radiation therapy (Brosius et al. 1981). Radiation therapy to the heart has also been associated with coronary artery spasm (Miller et al. 1983; YAHALOM et al. 1983). It is not known whether concurrent use of chemotherapy will increase the risk of coronary artery disease (BoIviN et al. 1992). The results of treatment appear to be the same in patients who did not undergo adjuvant radiation therapy (STEWART et al. 1995).

\subsubsection{3}

\section{Calcified Ascending Aorta}

Radiation therapy may give rise to calcifications of the ascending aorta after radiation-induced aortitis

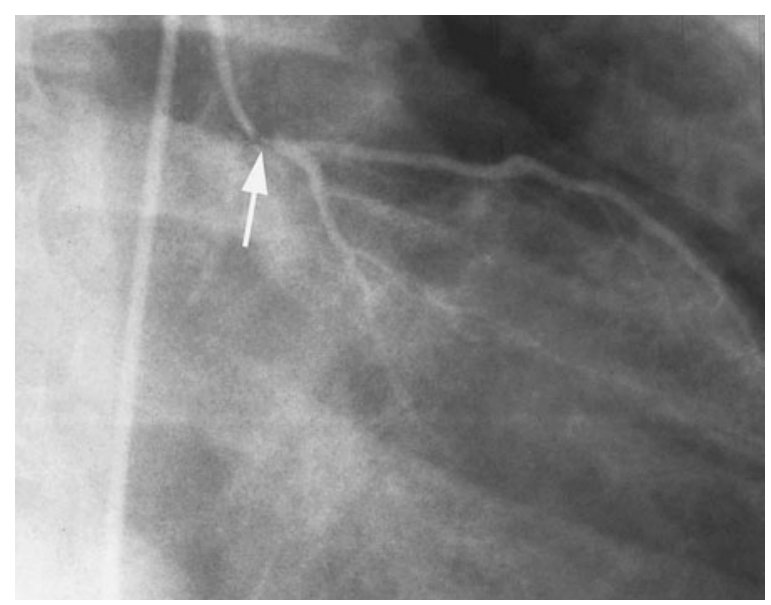

Fig. 23.24. Premature coronary artery stenosis in a non-smoking 27-year-old man fourteen years after radiation therapy for stage IV Hodgkin disease. Selective left coronary arteriogram shows a subocclusive ostial stenosis of the left main coronary artery (arrow). (With permission from [Mesurolle et al. 2000])
(Coblentz et al. 1986). The calcification has a fine, sharp, pencil-like outline. It is due to deposition of calcium salts in tissue as a sequela of a scarred intima or media after aortitis.

\subsubsection{4}

\section{Pericardial Disease}

Historically, the pericardium has been one of the most commonly affected structures of the heart (STEWART and FaJARDo 1984). Previously affecting $20-40 \%$ of patients with Hodgkin disease receiving irradiation with older techniques, the prevalence of post-radiation therapy pericarditis is now $2-6 \%$ and is very low when the radiation dose is below $40 \mathrm{~Gy}$, anterior and posterior fields are weighted equally, subcarinal blocking is used and daily fraction size is reduced $\leq 2.0 \mathrm{~Gy}$ (APPLEFELD et al. 1981). The frequency of pericarditis is significantly greater when a higher radiation dose is delivered per fraction for Hodgkin disease (Cosset et al. 1988). Early acute onset pericarditis is defined as occurring during radiotherapy and is associated with a large tumor contiguous to the heart (STEWART and FAJARdo 1984). This rare form is thought to be a reaction to necrosis of the tumor and has no long-term consequences (STEWART and FAJARDO 1984). Two delayed forms of pericarditis may occur as well. The most common form - pericardial effusion- appears 12-18 months after completion of radiation therapy (delayed acute form) (Fig. 23.25). The second form appears later, usually more than 48 months after radiation therapy, and manifests as chronic pericardial disease (delayed chronic form) (APPLEFELd et al. 1981). Most effusions clear spontaneously, but may take up to 2 years to do so. Constriction is observed in $15-20 \%$ of patients with delayed pericarditis (LOYer and Delpassand 1993), but it may arise in the absence of a prior adverse pericardial event (STEWART et al. 1995). The normal pericardium is thin, curvilinear, and 1-2 mm thick on CT (BULL et al. 1998). A pericardial thickness of $4 \mathrm{~mm}$ on CT or MR imaging is consistent with constriction. CT and MR imaging can provide information about impaired right ventricular diastolic filling when dilatation of the inferior vena cava and right atrium is demonstrated.

\subsubsection{5}

\section{Valvular Injuries and Conduction Abnormalities}

It is not clear whether radiation therapy causes structural alterations in valves (STEwART et al. 1995). These abnormalities are probably related to radiation or due to myocardial fibrosis adjacent to valve rings, resulting 


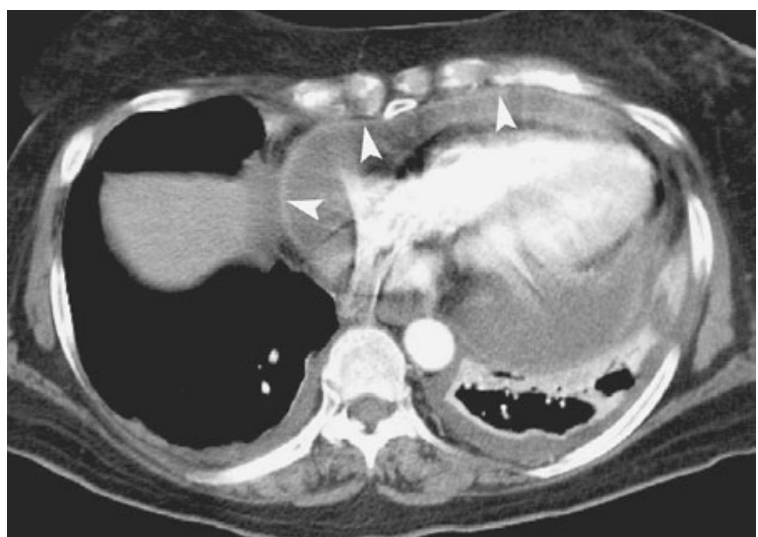

Fig. 23.25. Delayed post radiation pericarditis in a 52-year-old woman after mediastinal radiation therapy for non-Hodgkin lymphoma. Axial CT scan performed eighteen months after completion of radiation therapy shows a large amount of pericardial effusion and a diffuse thickening of the pericardium (arrowheads).

in distortion and functional impairment. The mitral, aortic, and tricuspid valves are the most frequently affected. Changes in cardiac rhythm are rarely seen, but the odd event has been attributed to ischemic fibrosis affecting the conduction system. Atrioventricular block, albeit rare, is the most frequent conduction abnormality encountered. It tends to occur about 10 years after treatment (usually after a radiation dose $\geq 40 \mathrm{~Gy}$ ) and requires insertion of a pacemaker in most cases (COHEN et al. 1981; Loyer and Delpassand 1993).

\subsection{4}

\section{Chest Wall and Nerve Injuries}

\subsubsection{1}

\section{Radiation-Induced Brachial Plexopathy}

In patients who undergo radiation therapy to the axillary region, the distinction between recurrent or residual disease and radiation-induced neuropathy can be difficult. Radiation fibrosis may occur generally 5-30 months after the completion of therapy with a peak at 10-20 months and is most likely to occur in patients who have received radiation doses in excess of $60 \mathrm{~Gy}$. Common symptoms include paresthesias, hyperesthesias, pain, and weakness. The utility of MR imaging is in part based on results showing that axillary areas of delayed radiation fibrosis are usually iso- or hypointense relative to muscle on T2-weighted images, thus distinguishing them from tumor infiltration, which is hyperintense (GLAZER et al. 1985). However, patients with post radiation plexopathy may have hyperintense signal in or near the plexus on T2-weighted images as frequently as patients with tumor infiltration (ThyAgARAJAN et al. 1995). Routine administration of gadolinium-based contrast material does not help differentiate radiation fibrosis from metastatic disease, because both may show some degree of enhancement (Wouter Van Es et al. 1997). Thus, the morphologic features of the signal abnormalities (absence of a focal mass, and stability of the findings on serial studies) rather than the hyper- or hyposignal, or enhancement, are the key findings that favor a diagnosis of radiation induced plexopathy over recurrent tumor or infection (BowEn et al. 1996).

\subsubsection{2 \\ Left Sided Vocal Cord Paralysis}

Anecdotal cases of left-side vocal cord paralysis in patients treated with mediastinal radiotherapy due to mediastinal fibrosis have been reported (Rosanowski 1995). The difference in anatomy of the left and the right recurrent nerve explains the prevalence of left side injuries.

\subsubsection{3 \\ Aseptic Necrosis and Osteochondroma}

Aseptic necrosis of the humeral heads has been reported after radiation therapy. The humeral heads can usually be blocked when mantle radiation is given (Rossleigh et al. 1986).

Osteochondroma is the only benign bone tumor related to radiation therapy. The prevalence of radiation-induced osteochondromas is about $12 \%$ in children whose epiphyses have been irradiated, whereas the prevalence of spontaneous osteochondromas is below $1 \%$. The majority of cases of radiation-induced osteochondromas have been associated with either orthovoltage or megavoltage therapies. The average latent period between radiation and identification of osteochondroma is 8 years ( $3-27$ years) after radiation (Gorospe et al. 2002). They tend to be solitary rather than multiple. They do not appear to be premalignant (Libshitz and Cohen 1967). In spinal locations, their detection is difficult on plain radiographs. CT can demonstrate the osseous component of the tumor but fails to show the cartilaginous cap in the majority of cases. MR imaging better evaluates the cartilaginous cap (cartilaginous malignant degeneration should be considered in cartilaginous caps more than $2 \mathrm{~cm}$ thick) and the intraspinal involvement (Gorospe et al. 2002). 


\section{4}

\section{Second Solid Neoplasms}

"It is a paradox that radiation can both cure and cause cancer" (AlEXANDER 1957). An increasing number of treatment-associated secondary neoplasms have long been recognized among long-term survivors of Hodgkin disease and non-Hodgkin lymphoma treated either with conventional chemotherapeutic agents or irradiation (BHATIA et al. 1996). However such complications have also been reported after HSCT (BHATIA et al. 2001). Such treatment-induced catastrophes are a consequence of one of the triumphs of cancer management. After HSCT, it is still unclear whether the malignancy is related to pretransplant chemotherapy and radiotherapy, the result of transplant conditioning regimens, or a cumulative effect of all of these factors.

The most commonly reported second malignancies include leukemia and non-Hodgkin lymphoma. Solid cancers have a longer latency period, and they are increasingly being described because of improved survival after treatment. After Hodgkin disease, the actuarial risk of cancer, 25 years after treatment, is $27.7 \%$ compared to $4.2 \%$ for the general population, at the same age. The relative risk of developing cancer, compared to the population, is estimated at 7 (37.5 for leukemia, 21.5 for lymphoma, 6 for solid tumor) (VAN LeEUWEN et al. 2000).

Solid tumors related to radiation-therapy occur in the irradiated field. Mantle irradiation should be avoided when possible in smokers and young women because of lung and breast cancer risks (AISENBERG 1999).

\subsection{1}

\section{Mesothelioma, Lung and Esophageal Carcinomas}

Radiation-induced mesothelioma and lung carcinoma have been described (Hofmann et al. 1994; Neugut et al. 1994). A two- to eightfold risk of lung carcinoma (compared with the risk in the general population) is observed 5 or more years after Hodgkin disease treatment and persists through the second decade (VAN LeEuwen et al. 1994). There is general agreement of the excess risk after irradiation and combined regimens of alkylating agents (VAN LEEUWEN et al. 1994) with a direct relationship between lung cancer risk and dose to the previously irradiated lung segments (VAN LEeUwen et al. 1995). The interval between radiation therapy and the appearance of mesothelioma ranges from 5 to 41 years (median 13.5 years) (HofmanN et al. 1994).
Radiographic and CT features are non-specific and consist of pleural effusion with or without pleuralbased masses (HoFmanN et al. 1994).

Radiation-induced esophageal carcinoma has been described (Micke et al. 1999; Audebert et al. 2002). The interval between radiation therapy and the appearance of esophageal carcinoma ranges from 5 to 30 years (AUDEBERT et al. 2002). Imaging features are similar to those of other esophageal squamous cell carcinomas (AUDEBERT et al. 2002). These cancers, which are almost all symptomatic, have a poor prognosis.

\subsection{2 \\ Breast Carcinoma}

Women who undergo thoracic irradiation before age 30 have a high risk of developing a second breast cancer. In the study of BHATIA et al. (1996), women treated for childhood Hodgkin disease had a risk of breast cancer 75 times greater than that of the general population. Breast sensitivity to radiation disappears if the first exposure occurs after 35 years of age. The first breast carcinomas appear at the end of the first decade after Hodgkin disease irradiation. The mean interval between exposure and the development of breast cancer is 15-19 years. Data on the relationship between the radiation field and breast cancer are inconsistent, but the tumor usually appears within or at the edge of treatment fields. YAHALOM et al. (1992) found a higher percentage of breast cancers in the inner quadrants; in the study of DeRshaw et al. (1992), the main site was the upper outer quadrant, with equal distribution between the left and right breasts. Women who undergo thoracic irradiation before the age of 30 years should benefit from screening with mammography earlier than the general population. Any abnormal clinical or mammographic finding should prompt a histologic examination (Fig. 23.26).

\subsection{3}

\section{Sarcomas}

Radiation-induced sarcomas are an infrequent but well-recognized complication of radiation therapy. They were demonstrated in an experimental study conducted by MARIE et al. (1910). The risk of post-radiation therapy sarcoma is very low relative to the beneficial effects of radiation therapy, but they deserve attention because of their often unfavorable 

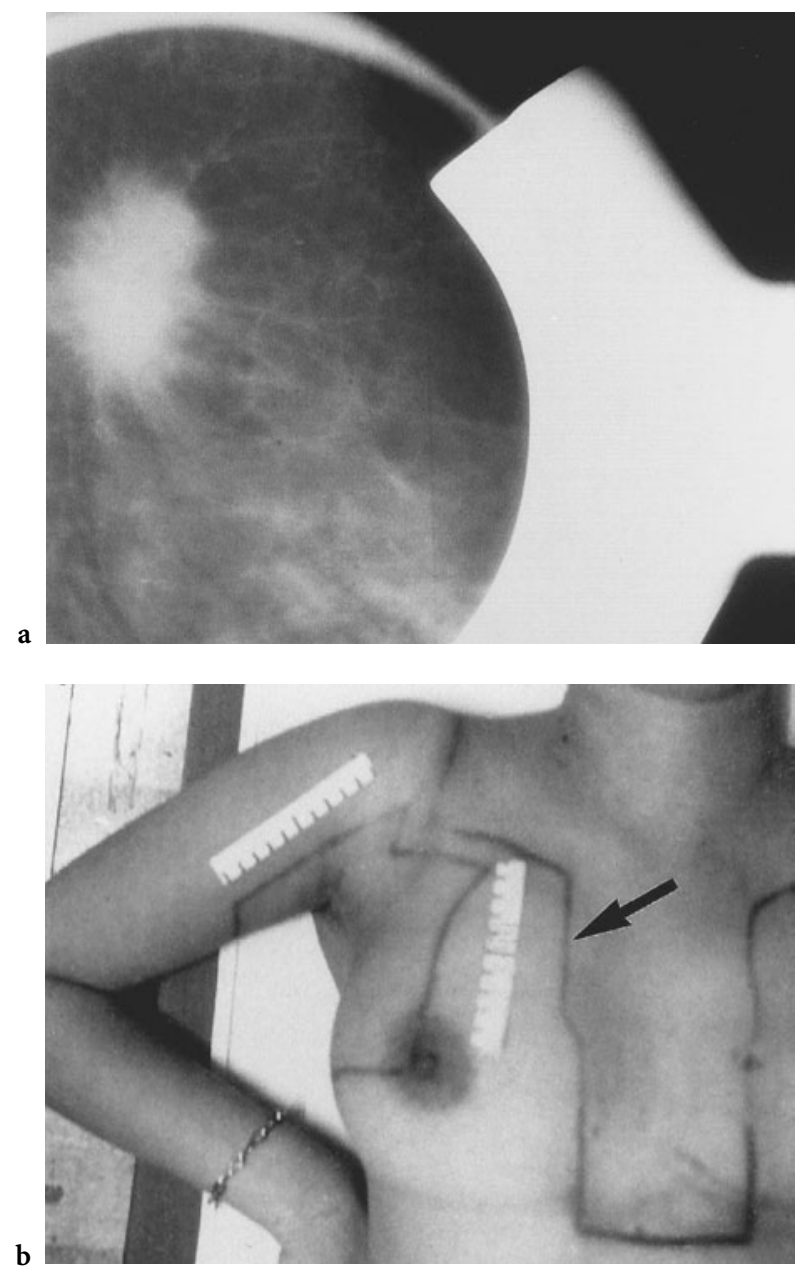

Fig. 23.26a,b. Breast cancer in a 47-year-old woman who underwent radiation therapy at the age 23 for Hodgkin disease. At clinical examination, there was a palpable nodule in the right upper inner quadrant, which yielded an infiltrating ductal carcinoma at histology. a Lateral mammogram shows a spiculated area of increased opacity. b A pretreatment photograph shows the radiation fields for the treatment of Hodgkin disease. The site of the future breast cancer (arrow) overlaps the radiation field. (With permission from [MESurolle et al. 2000])

outcome when they occur after Hodgkin disease irradiation. The risk of radiation-induced sarcoma is not greater than the risk of death due to surgery or anesthesia (PARKER 1990). Radiation-induced sarcomas occur in approximately $0.1 \%$ or fewer of patients who receive radiation therapy and survive 5 years, but constitute a particularly important group of treatment induced neoplasms in the pediatric and adolescent Hodgkin disease population (TUCKER et al. 1987). Such sarcomas can occur 3-30 years after completion of radiation therapy in either bone or soft tissue. Osteosarcoma is the most frequent variety occurring in bone, and malignant fibrous histiocytoma is the most common cell type arising in soft tissue (Libshitz 1994).

\subsubsection{1}

\section{Diagnosis of Radiation-Induced Bone Sarcoma}

Criteria for diagnosis of a radiation-induced sarcoma arising in bone are: (a) a history of radiation therapy; (b) a neoplasm arising within the irradiated area; (c) a number of years of latency; and (d) histologic proof of sarcoma (CAHAN et al. 1948).

\subsubsection{2}

\section{Factors Related to Radiation-Induced Sarcomas}

A minimal dose, should one exist, has not been defined. Most patients included in earlier studies received orthovoltage radiation therapy. Today, most patients receive megavoltage radiation therapy. The energy attenuation in bone achieved with megavoltage radiation therapy should result in fewer radiation-induced soft-tissue sarcomas. It is not known whether chemotherapy compounds the risk of developing a radiation-induced sarcoma.

\subsubsection{3 \\ Imaging Appearance}

Radiation-induced sarcomas are aggressive, with a marked tendency toward local recurrence and distant metastasis (Fig. 23.27) (SoubA et al. 1986). Salvage therapy could be successful in some patients, but early diagnosis is necessary. On radiography, radiation-induced sarcomas of bone do not differ from de novo sarcomas (SMITH 1982), appearing most frequently as an area of bone destruction on conventional radiographs. A radiation-induced sarcoma should be suspected when changes occur in the appearance of previously stable irradiated bone, particularly if an associated soft-tissue mass is present. On CT or MR imaging, a soft-tissue mass and bone destruction are the most common findings (LORIGAN et al. 1989). The differential diagnosis includes metastases, infection, and severe benign changes. Involvement of bone outside the treatment field indicates metastatic disease. Absence of a soft-tissue mass is the most helpful finding in distinguishing extensive benign changes from a radiation-induced sarcoma. Nevertheless, histologic proof is mandatory in all cases. 
a
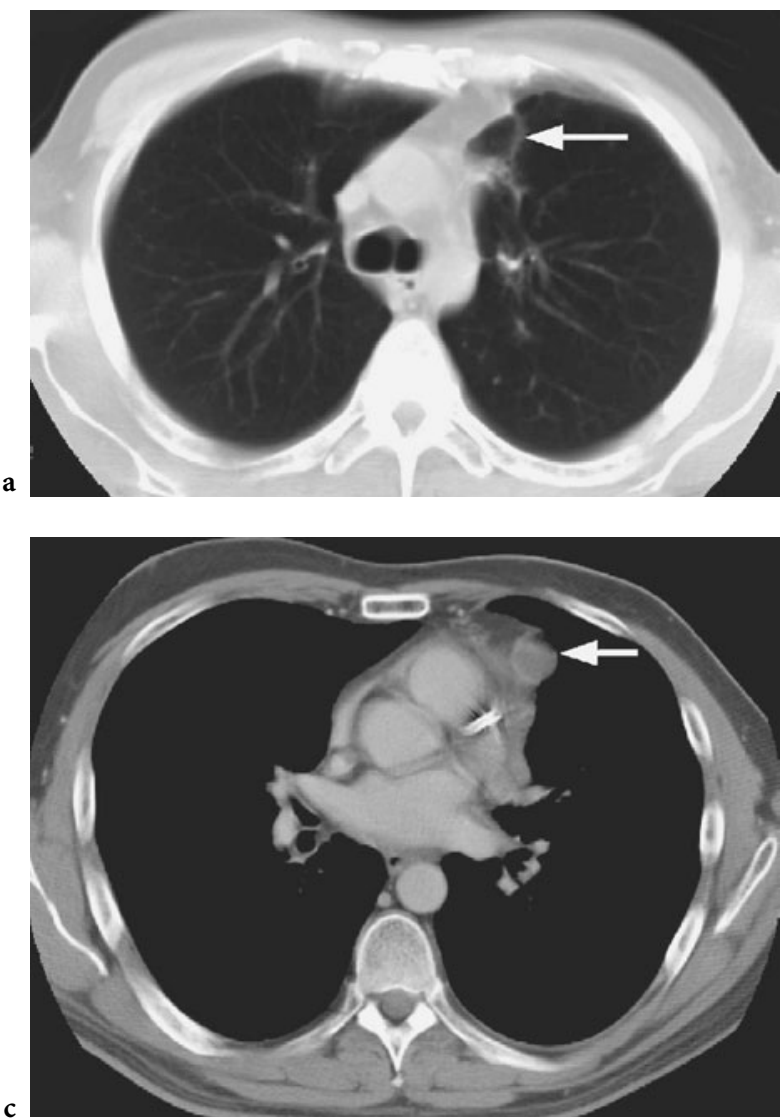

\section{5}

\section{Residual Masses and Thymic Rebound}

\subsection{1}

\section{Residual Mediastinal Masses}

The main therapeutic objective in the treatment of lymphoma is to achieve a complete response, which is associated with a longer disease-free survival and a favorable outcome. Response to treatment is assessed by clinical, imaging and pathological criteria (Cheson et al. 1999). Defining a complete response on CT, however, may be difficult. Residual mediastinal masses are frequently observed (10-20\%) on CT scans in patients with mediastinal lymphoma after completed therapy, particularly in patients who initially have bulky masses (TREDANIEL et al. 1992). A residual mass detected on CT after treatment may contain viable tumor cells or, alternatively, may consist of only fibrotic or necrotic tissue. Therefore a common clinical problem arises when a residual abnormality persists on follow-up CT, in spite of the disappearance of clinical symptoms and the reversion of laboratory tests to normal values. The overall

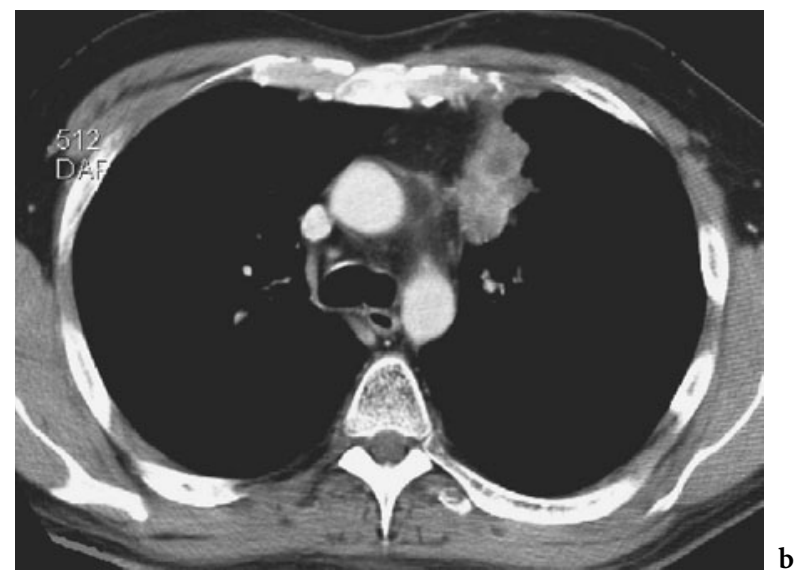

Fig. 23.27a-c. Thoracic sarcoma in a 47-year-old man fifteen years after radiation therapy for Hodgkin disease. a Axial CT scan nine years after completion of radiation therapy showing post radiation changes of the left upper lobe confined to the radiation port with hilar retraction and linear fibrosis (arrow). b Axial CT scan thirteen years after completion of radiation therapy demonstrates occurrence of a mass located within the radiation field. Biopsy shows evidence of post-radiation highgrade sarcoma. c More caudal axial CT scan shows extension of the disease along the anterior portion of the pericardium (arrow). Note the presence of a coronary stent located within the left anterior descending branch. This coronary stenosis is most likely related to the radiation therapy.

prognosis of patients with residual active disease is poor, and further second-line therapeutic regimens should be initiated as early as possible. In contrast, a benign residual mass is associated with a favorable prognosis and does not warrant any additional treatment (ZinZANi et al. 2001). Apart from calcification of a nonenlarged mass after radiation therapy, which signifies a favorable response to therapy (Fig. 23.28) (KATZ et al. 1977), anatomic imaging with CT does not consistently distinguish between dividing tumor cells and post-therapy fibrosis. Gallium-67 scintigraphy has been shown to be more sensitive for lesions in the chest and to accurately demonstrate active residual disease when there is uptake of Gallium-67 in high-grade non-Hodgkin lymphoma and Hodgkin disease (Kostakoglu et al. 1992; Kostakoglu et al. 2002). However Gallium-67 scintigraphy suffers from the low resolution of the single-photon emission tomography technique in tumors smaller than $2 \mathrm{~cm}$, and false positives have been reported in cases of infection or recent surgery (GASPERINI et al. 1993). MR imaging has been evaluated and compared to Gallium-67 scintigraphy, but it is no better for predicting relapses (Hill et al. 1993). Active tumor foci may be 

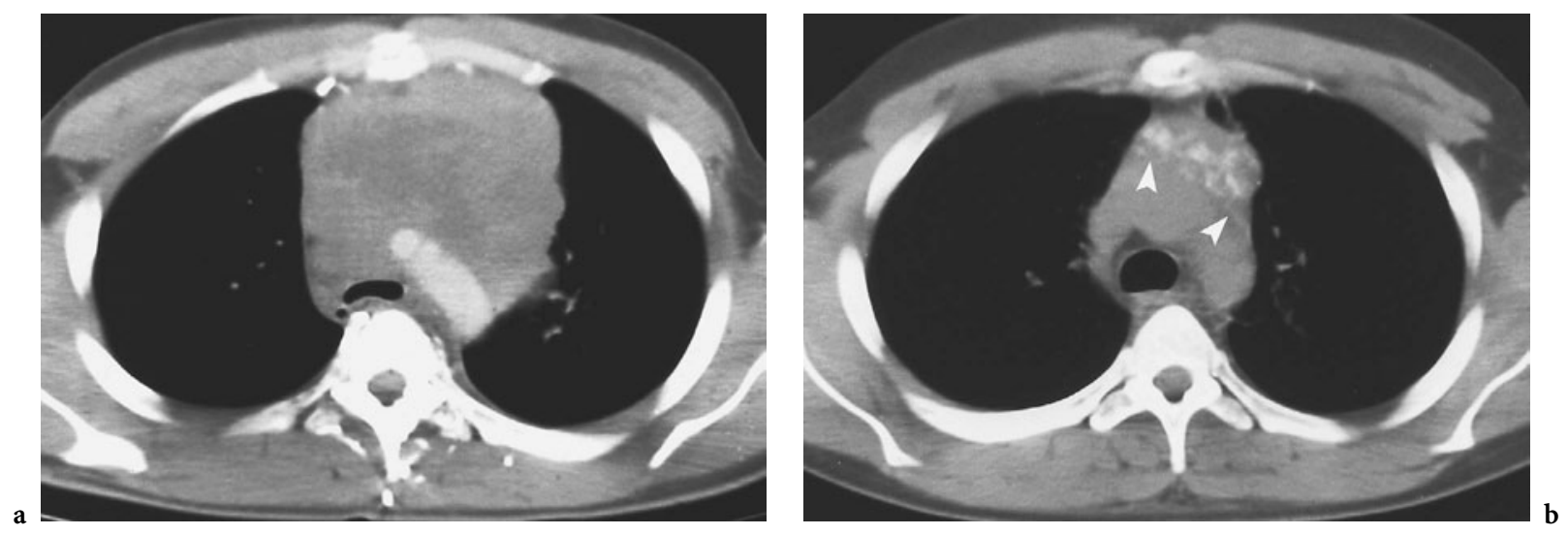

Fig. 23.28a,b. Residual mediastinal mass in a 35-year-old man treated for non Hodgkin lymphoma. a Pretreatment axial contrast-enhanced CT scan shows large anterior mediastinal mass. b Axial unenhanced CT scan performed eleven months after completion of chemotherapy and radiation therapy shows a residual calcified nonactive mediastinal mass (arrowheads).

found within a residual mass with low signal intensity on T2-weighted images. Necrosis, immature fibrotic tissue, edema, and inflammation associated with responding disease can simulate the hyperintensity of a viable tumor, particularly within the first 6 months after therapy. MR imaging evaluation of residual masses requires a pretreatment baseline study for comparison, including both T2-weighting and contrast-enhanced sequences (RAHMOUNI et al. 2001). $18 \mathrm{~F}$-fluorodeoxyglucose (FDG) is a glucose analog known to localize in active lymphoma. Metabolic imaging with FDG positron emission tomography (PET) is gaining in popularity and has proven to have a high sensitivity for the detection of residual tumor and is now a mainstay for treatment evaluation in centers at which this technology is available (SPAEPEN and Mortelmans 2001; Naumann et al. 2001). It is the most effective means of detecting residual tumor after therapy (Fig. 23.29). Recent studies indicate that the positive predictive value of FDG-PET in lymphoma post therapy is greater than $90 \%$, and that the negative predictive value is slightly lower (DE WIT et al. 1997; Jerusalem et al. 1999; Mikhaeel et al. 2000).

\subsection{2}

\section{Thymic Rebound Hyperplasia}

Excessive regrowth of the thymus after chemotherapy, also called thymic rebound hyperplasia (regrowth should be 50\% greater than baseline volume) is a rare but well described phenomenon seen in children and young adults (Сноуке et al. 1987). The size of the thymus appears to be extremely sensitive to chemotherapy as the thymus atrophies during the administration of chemotherapy, with regrowth during the recovery phase of chemotherapy (LANGER et al. 1992; CHOYKe et al. 1987). It is generally asymptomatic and detected accidentally as a mediastinal mass on CT scan. There is no reliable non-invasive technique to distinguish thymic rebound hyperplasia from residual or recurrent tumor. It is well known that gallium accumulates in the hyperplastic thymus, inducing false positive Gallium-67 scintigraphy results. The low resolution of Gallium-67 scintigraphy can make it difficult to differentiate homogeneous physiologic uptake of the thymus from irregular uptake seen in mediastinal lymphadenopathy (PEYLAN-RAmu et al. 1989). A steroid trial has been suggested but should be used cautiously as some lymphomas are steroid-sensitive (Ford et al. 1987). False positive Thallium-201 uptake has been reported as well. In fact, if thymic rebound hyperplasia is suspected because the patient is doing well clinically with no recurrent or residual disease evident in other locations, follow-up imaging is an acceptable method of clarifying the cause of thymic enlargement (Fig. 23.30). Indeed, a gradual reduction in size corroborates the benign cause of the enlargement (Roebuck et al. 1998).

\section{6 \\ Transfusion-Related Acute Lung Injury}

Transfusion-related acute lung injury (TRALI) is a rare life-threatening complication (fatal in $5-10 \%$ 


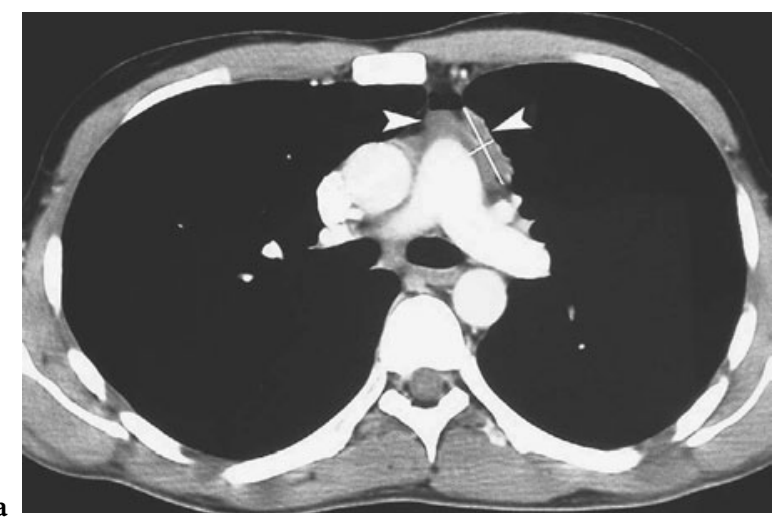

Fig. 23.29a,b. Residual mediastinal mass in a 32-year-old man after chemotherapy for Hodgkin disease. a Axial CT scan performed at the end of treatment shows a residual anterior mediastinal mass (arrowheads). b Coronal FDG-PET scan of this patient is negative. Note physiologic uptakes in the cerebral cortex, liver, spleen, and urinary bladder, and also the minimal uptake in the bone marrow. This mass remained stable on follow-up CT examinations.

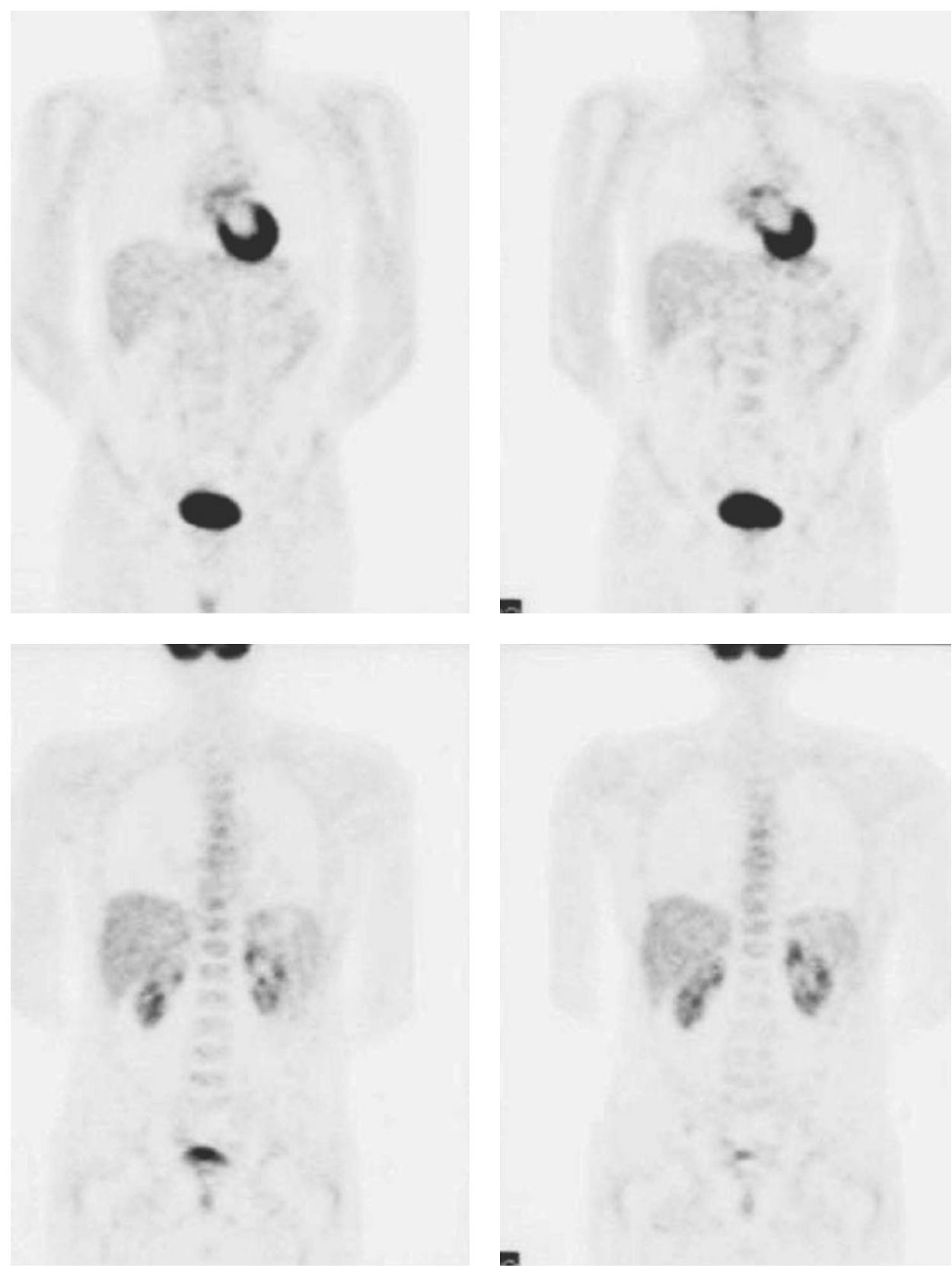


a
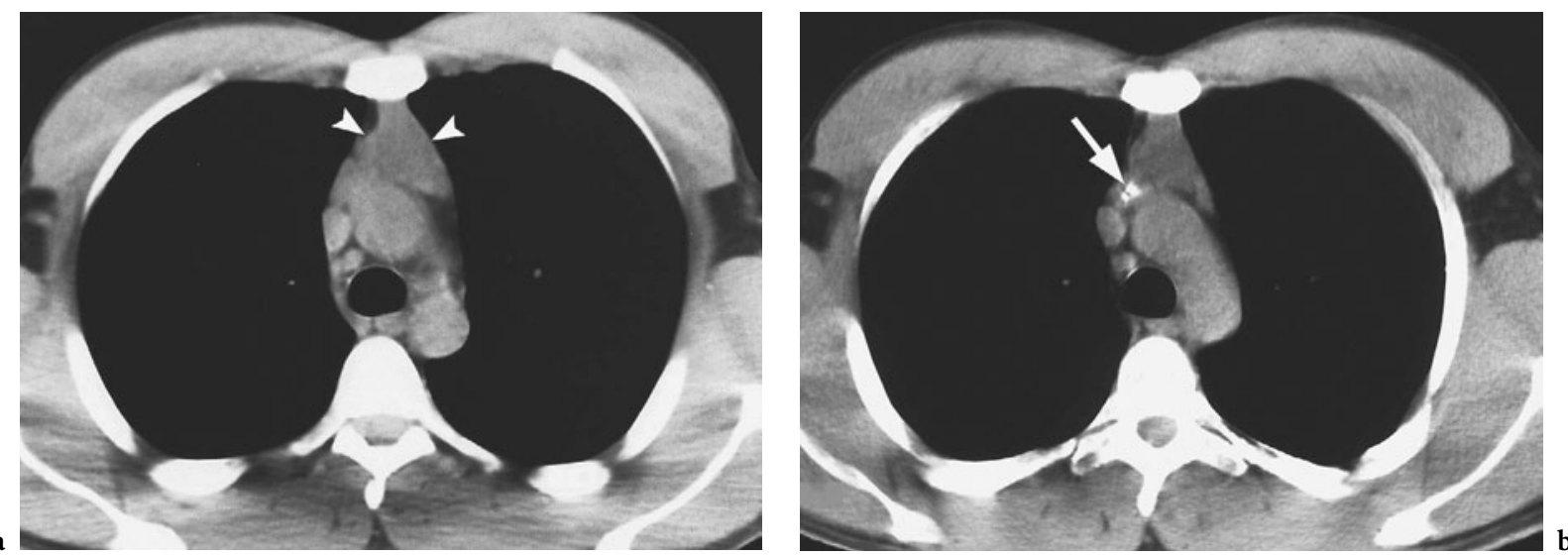

Fig. 23.30a,b. Thymic rebound in a 25 -year-old man treated for non-Hodgkin lymphoma. A CT scan performed three months after completion of treatment showed a small residual mediastinal mass. a Axial unenhanced CT scan performed six months after completion of the treatment shows enlargement of the thymus (arrowheads). b Axial unenhanced CT scan performed eighteen months after completion of the treatment shows an unchanged thymic hyperplasia, associated with early stage of calcifications in residual mass (arrow).

of cases) occurring within 6 hours of transfusion of a plasma-containing blood product. Patients with underlying hematologic malignancy appear to be at risk (Popovsky and Moore 1985; Silliman et al. 2003). TRALI consists of the insidious onset of pulmonary insufficiency, manifested by severe dyspnea and hypoxia with normal cardiac function. Chest radiographs classically demonstrate pulmonary edema with "white-out" by interstitial and alveolar infiltrates similar to that seen in acute respiratory distress syndrome (Fig. 23.31), but in the first few hours, a patchy pattern may be observed. The key to distinguishing TRALI from other forms of pulmonary edema is recognition that the pulmonary edema is noncardiogenic and that affected patients do not have volume overload (Popovsky 2001).

\section{7}

\section{Conclusion}

Various changes in the thorax can occur in patients with hematological malignancies in relation to the course and/or the phase of therapy. After chemotherapy or/and HSCT, chest CT, especially HRCT, is more sensitive and specific than plain radiography in the assessment of both acute and late complica-

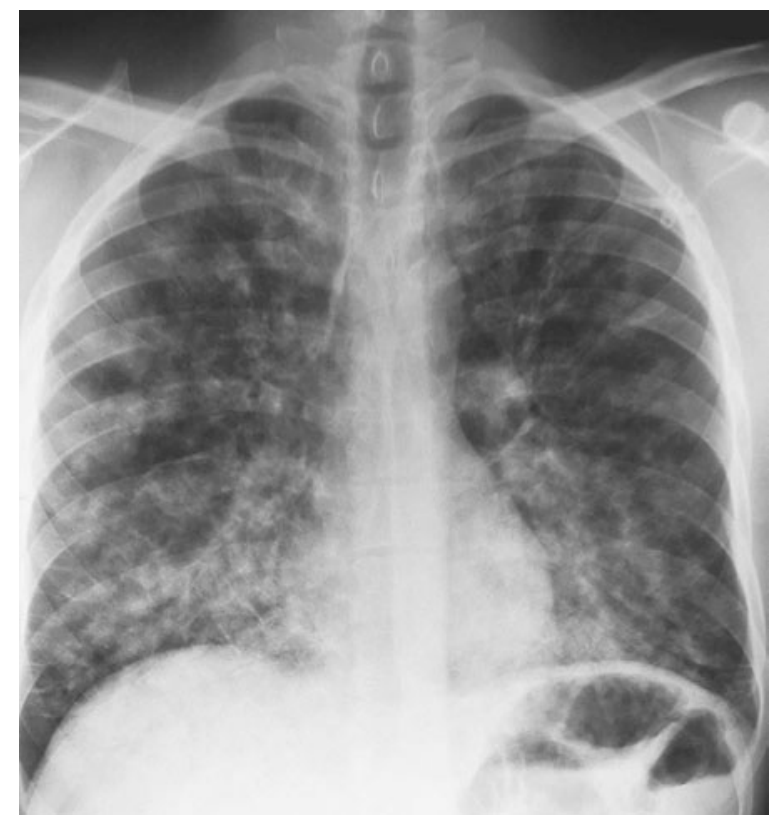

Fig. 23.31. Transfusion-related acute lung injury in a 38-yearold man at the time of induction for an acute B-cell lymphoblastic leukemia. The patient developed a dyspnea two hours after a platelet transfusion. Posteroanterior chest radiograph before transfusion was normal (not shown). Posteroanterior chest radiograph performed six hours after transfusion shows extensive and bilateral mixed alveolar and interstitial opacities consistent with a pulmonary edema. tions. Despite the fact that many chest complications show non-specific and overlapping HRCT findings including ground-glass opacity and airspace consolidation, HRCT narrows the differential diagnosis 
and suggests further diagnostic evaluation such as bronchoalveolar lavage and lung biopsy.

CT scan and Gallium-67 scintigraphy are considered the restaging methods of choice for patients with mediastinal lymphoma. Gallium-67 scintigraphy should be routinely used for early identification of any residual disease after induction so as to allow timely initiation of the appropriate form of secondline treatment. In case of indeterminate lesions on CT scan and Gallium-67 scintigraphy, PET has proven to have a high-sensitivity for the detection of residual tumor.

Large numbers of patients now survive for years following both conventional therapy (chemotherapy and radiation therapy) and HSCT, and several late effects of treatment are now becoming evident. Radiation-induced changes are usually diagnosed on the basis of their characteristic appearance at CT and knowledge of the radiation ports, radiation dose, and interval since therapy. Most importantly, all patients in whom long-term survival is expected should be monitored closely with vigilance regarding potentially lethal iatrogenic complications, such as second cancers and cardiovascular complications, even long after the original disease appears to be cured.

\section{References}

Aisenberg AC (1999) Problems in Hodgkin's disease management. Blood 93:761-779

Alexander P (1957) Atomic radiation and life, 1st edn. Penguin Books, Baltimore

Applefeld MM, Cole JF, Pollock SH, et al. (1981) The late appearance of chronic pericardial disease in patients treated by radiotherapy for Hodgkin's disease. Ann Intern Med 94:338-341

Audebert A, Sauvanet A, Mauvais F, et al. (2002) Radiationinduced esophageal carcinoma: report of 11 cases. Ann Chir 127:289-296

Baron RL, Sagel SS, Baglan RJ, et al. (1981) Thymic cysts following radiation therapy for Hodgkin's disease. Radiology 141:593-597

Benson EP (1973) Radiation injury of large arteries: 3 further examples with prolonged asymptomatic intervals. Radiology 106:195-197

Bereton HD, Johnson RE (1974) Calcification in mediastinal lymph nodes after radiation therapy of Hodgkin's disease. Radiology 112:705-707

Bhatia S, Louie AD, Bhatia R, et al. (2001) Solid cancers after bone marrow transplantation. J Clin Oncol 19:464-471

Bhatia S, Robison LL, Oberlin O, et al. (1996) Breast cancer and other second neoplasms after childhood Hodgkin's disease. N Engl J Med 334:745-751

Bodey GP, Powell RD Jr, Hersh EM, et al. (1996) Pulmonary complications of acute leukemia. Cancer 19: 781-793
Boiselle PM, Crans CA, Kaplan MA (1999) The changing face of Pneumocystis carinii pneumonia in AIDS patients. AJR Am J Roentgenol 172:1301-1309

Boivin JF, Hutchison GB (1982) Coronary heart disease mortality after irradiation for Hodgkin's disease. Cancer 49: 2470-2475

Boivin JF, Hutchison GB, Lubin JH, et al. (1992) Coronary artery disease mortality in patients treated for Hodgkin's disease. Cancer 69:1241-1247

Bowen BC, Verma A, Brandon AH, et al. (1996) Radiationinduced brachial plexopathy: MR and clinical findings. AJNR Am J Neuroradiol 17:1932-1936

Brady LW, Levitt SH (1998) Radiation oncology in the 3rd millennium. Radiology 209:593-596

Brice P, Tredaniel J, Monsuez JJ, et al. (1991) Cardiopulmonary toxicity after three courses of ABVD and mediastinal irradiation in favorable Hodgkin's disease. Ann Oncol 2 (suppl 2):73-76

Brosius FC, Waller BF, Roberts WC, et al. (1981) Radiation heart disease. Am J Med 70:519-530

Buff SJ, McLelland R, Gallis HA, et al. (1982) Candida albicans pneumonia: Radiographic appearance. AJR Am J Roentgenol 138: 645-648

Bull RK, Edwards PD, Dixon AK, et al. (1998) CT dimensions of the normal pericardium. Br J Radiol 71:923-925

Cahan WG, Woodard HQ, Hiinbotham NL, et al. (1948) Sarcoma arising in irradiated bone. Cancer 1:3-29

Cheson BD, Horning SJ, Coiffier B, et al. (1999) Report of an international workshop to standardize response criteria for non-Hodgkin's lymphomas. NCI Sponsored International Working Group. J Clin Oncol 17:1244-1253

Choyke PL, Zeman RK, Gootenberg JE, et al. (1987) Thymic atrophy and regrowth in response to chemotherapy: CT evaluation. AJR Am J Roentgenol 149:269-272

Clark JG, Hansen JA, Hertz MI, et al. (1993) Idiopathic pneumonia syndrome after bone marrow transplantation. Am Rev Respir Dis 147:1601-1606

Coblentz C, Martin L, Tuttle R, et al. (1986) Calcification of the ascending aorta after radiation therapy. AJR Am J Roentgenol 147:477-478

Cohen SI, Bharati S, Glass J, et al. (1981) Radiotherapy as a cause of complete atrioventricular block in Hodgkin's disease: an electrophysiological-pathological correlation. Arch Intern Med 141:676-679

Coia LR, Myerson RJ, Tepper JE, et al. (1995) Late effects of radiation therapy on the gastrointestinal tract. Int J Radiat Oncol Biol Phys 30:1213-1236

Cosset JM, Henry-Amar M, Girinski T, et al. (1988) Late toxicity of radiotherapy in Hodgkin's disease: the role of fraction size. Acta Oncol 27:123-129

Cosset JM, Henry-Amar M, Pellae-Cosset B, et al. (1991) Pericarditis and myocardial infarction after Hodgkin's disease therapy. Int J Radiat Oncol Biol Phys 21:447-449

Dershaw DD, Yahalom J, Petrec JA (1992) Breast carcinoma in women previously treated for Hodgkin disease: mammographic evaluation. Radiology 184:421-423

de Wit M, Bumann D, Beyer W, Herbst K, et al. (1997) Wholebody positron emission tomography (PET) for diagnosis of residual mass in patients with lymphoma. Ann Oncol 8 (Suppl 1):57-60

Dubois PJ, Myerowitz RL, Allen CM (1977) Pathoradiologic correlation of pulmonary candidiasis in immunosuppressed patients. Cancer 40:1026-1036 
Fajardo LF, Berthrong M (1988) Vascular lesions following radiation. Pathol Annu 23:297-330

Fajardo LF, Lee A (1975) Rupture of major vessels after radiation. Cancer 36:904-913

Ford EG, Lockhart SK, Sullivan MP, et al. (1987) Mediastinal mass following chemotherapeutic treatment of Hodgkin's disease: recurrent tumor or thymic hyperplasia? J Pediatr Surg 22:1155-1159

Gasparini MD, Balzarini L, Castellani MR, et al. (1993) Current role of gallium scan and magnetic resonance imaging in the management of mediastinal Hodgkin lymphoma. Cancer 72:577-582

Gefter WB, Albelda SM, Talbot GH, et al. (1985) Invasive pulmonary aspergillosis and acute leukemia. Limitations in the diagnostic utility of the air crescent sign. Radiology 157:605-610

Girinsky T, Cordova A, Rey A, Cosset JM, et al. (2000) Thallium-201 scintigraphy is not predictive of late cardiac complications in patients with Hodgkin's disease treated with mediastinal radiation. Int J Radiat Oncol Biol Phys 48:1503-1506

Glazer HS, Lee JK, Levitt RG, et al. (1985) Radiation fibrosis: differentiation from recurrent tumor by MR imaging-work in progress. Radiology 156:721-726

Gorospe L, Madrid-Muniz C, Royo A, et al. (2002) Radiationinduced osteochondroma of the T4 vertebra causing spinal cord compression. Eur Radiol 12:844-848

Gruden JF, Huang L, Turner J, et al. (1997) High-resolution CT in the evaluation of clinically suspected pneumocystis carinii pneumonia in AIDS patients with normal, equivocal, or nonspecific radiographic findings. AJR Am J Roentgenol 169:967-975

Hancock SL, Tucker MA, Hoppe RT (1993) Factors affecting late mortality from heart disease after treatment of Hodgkin's disease. JAMA 270:1949-1955

Hasleton PS and Doran HM (1996) Pulmonary changes after transplantation. In: Hasleton PS (ed) Spencer's pathology of the lung. McGraw-Hill, New York, pp 723-765

Hildebrand FL Jr, Rosenow EC 3rd, Habermann TM, et al. (1990) Pulmonary complications of leukemia. Chest 98: 1233-1239

Hill M, Cunningham D, MacVicar D, et al. (1993) Role of magnetic resonance imaging in predicting relapse in residual masses after treatment of lymphoma. J Clin Oncol 11: 2273-2278

Hofmann J, Mintzer D, Warhol MJ (1994) Malignant mesothelioma following radiation therapy. Am J Med 97:379-382

Hows JM (2001) Status of umbilical cord blood transplantation in the year 2001. J Clin Pathol 54:428-434

Ichikado K, Johkoh T, Ikezoe J, et al. (1997) Acute interstitial pneumonia: high-resolution CT findings correlated with pathology. AJR Am J Roentgenol 168:333-338

Ikezoe J, Takashima S, Morimoto S, et al. (1988) CT appearance of acute radiation-induced injury in the lung. AJR Am J Roentgenol 150:765-770

Ikezoe J, Takeuchi N, Johkoh T, et al. (1992) CT appearance of pulmonary tuberculosis in diabetic and immunocompromised patients: Comparison with patients who had no underlying disease. AJR Am J Roentgenol 159:1175-1179

Jerusalem G, Beguin Y, Fassotte MF, et al. (1999) Whole-body positron emission tomography using $18 \mathrm{~F}$-fluorodeoxyglucose for posttreatment evaluation in Hodgkin's disease and non-Hodgkin's lymphoma has higher diagnostic and prognostic value than classical computed tomography scan imaging. Blood 94:429-433

Kang EY, Patz EF, Müller NL (1996) Cytomegalovirus pneumonia in transplant patients: CT findings. J Comput Assist Tomogr 20:295-299

Katz M, Piekarski JD, Bayle-Weisberger C, et al. (1977) Residual mediastinal mass following radiation therapy for Hodgkin's disease. Ann Radiol 20:667-672

Kopelson G, Herwig KJ (1978) Coronary artery disease in cancer patients. Int J Radiat Oncol Biol Phys 4:895-906

Kostakoglu L, Leonard JP, Kuji I, et al. (2002) Comparison of fluorine-18 fluorodeoxyglucose positron emission tomography and Ga-67 scintigraphy in evaluation of lymphoma. Cancer 94:879-888

Kostakoglu L, Yeh SD, Portlock C, et al. (1992) Validation of gallium-67-citrate single-photon emission computed tomography in biopsy-confirmed residual Hodgkin's disease in the mediastinum. J Nucl Med 33:345-350

Krowka MJ, Rosenow EC, Hoagland HC (1985) Pulmonary complications of bone marrow transplantation. Chest 87: 237-245

Kuhlman JE, Fishman EK, Siegelman SS (1985) Invasive pulmonary aspergillosis in acute leukemia: characteristic findings on CT, the CT halo sign, and the role of CT in early diagnosis. Radiology 157:611-614

Kuhlman JE, Fishman EK, Burch PA, et al. (1988) CT of invasive pulmonary aspergillosis. AJR Am J Roentgenol 150: $1015-1020$

Kuhlman JE, Kavuru M, Fishman EK, et al. (1990) Pneumocystis carinii pneumonia: Spectrum of parenchymal CT findings. Radiology 175:711-714

Langer CJ, Keller SM, Erner SM (1992) Thymic hyperplasia with hemorrhage simulating recurrent Hodgkin's disease after chemotherapy-induced complete remission. Cancer 70:2082-2086

Lau DM, Siegel MJ, Hildebolt CF, et al. (1998) Bronchiolitis obliterans syndrome: Thin-section CT diagnosis of obstructive changes in infants and young children after lung transplantation. Radiology 208:783-788

Lee CK, Aeppli D, Nierengarten ME (2000) The need for longterm surveillance for patients treated with curative radiotherapy for Hodgkin's disease: University of Minnesota experience. Int J Radiat Oncol Biol Phys 48:169-179

Lepke RA, Libshitz HI (1983) Radiation-induced injury of esophagus. Radiology 148:375-378

Libshitz HI (1993) Radiation changes in the lung. Semin Roentgenol 28:303-320

Libshitz HI (1994) Radiation changes in bone. Semin Roentgenol 29:15-37

Libshitz HI, Brosof AB, Southard ME (1973) Radiographic appearance of the chest following extended field radiation therapy for Hodgkin's disease. A consideration of timedose relationships. Cancer 32:206-215

Libshitz HI, Cohen MA (1967) Radiation-induced osteochondromas. Radiology 142:750-760

Libshitz HI, Shuman LS (1984) Radiation-induced pulmonary change: CT findings. J Comput Assist Tomogr 8:15-19

Logan PM (1998) Thoracic manifestations of external beam radiotherapy. AJR Am J Roentgenol 171:569-577

Lorigan JG, Libshitz HI, Peuchot M (1989) Radiation-induced sarcoma in bone: CT findings in 19 cases. AJR Am J Roentgenol 153:791-794 
Loyer EM, Delpassand ES (1993) Radiation-induced heart disease: imaging features. Semin Roentgenol 28:321-332

Loyer E, Fuller L, Libshitz HI, et al. (2000) Radiographic appearance of the chest following therapy for Hodgkin disease. Eur J Radiol 35:136-148

Marie P, Clunet J, Raulot-Lapointe G (1910) Contribution à l'étude du développement des tumeurs malignes sur les ulcères de Roentgen. Bull Assoc France Etude Cancer 3: 404-426

McAdams HP, Rosado de Christenson M, Strollo DC, et al. (1997) Pulmonary mucormycosis: radiologic findings in 32 cases. AJR Am J Roentgenol 168:1541-1548

McGuinness G, Scholes JV, Garay SM, et al. (1994) Cytomegalovirus pneumonitis: spectrum of parenchymal CT findings with pathologic correlation in 21 AIDS patients. Radiology 192:451-459

McKee LC Jr, Collins RD (1974) Intravascular leukocyte thrombi and aggregates as a cause of morbidity and mortality in leukemia. Medicine Baltimore 53:463-478

Mesurolle B, Qanadli SD, Merad M, et al. (2000) Unusual radiologic findings in the thorax after radiation therapy. Radiographics 20:67-81

Micke O, Schafer U, Glashorster M, et al. (1999) Radiationinduced esophageal carcinoma 30 years after mediastinal irradiation: case report and review of the literature. Jpn J Clin Oncol 29:164-170

Mikhaeel NG, Timothy AR, O’Doherty MJ, et al. (2000) 18FDG-PET as a prognostic indicator in the treatment of aggressive Non-Hodgkin's Lymphoma-comparison with CT. Leuk Lymphoma 39:543-553

Miller DD, Waters DD, Dangoisse V, et al. (1983) Symptomatic coronary artery spasm following radiation for Hodgkin's disease. Chest 83:284-285

Mosvas B, Raffin TA, Epstein AH, et al. (1997) Pulmonary radiation injury. Chest 111:1061-1076

Naumann R, Vaic A, Beuthien-Baumann B, et al. (2001) Prognostic value of positron emission tomography in the evaluation of post-treatment residual mass in patients with Hodgkin's disease and non-Hodgkin's lymphoma. $\mathrm{Br}$ J Haematol 115:793-800

Neugut AI, Murray T, Santos J, et al. (1994) Increased risk of lung cancer after breast cancer radiation therapy in cigarette smokers. Cancer 73:1615-1620

Nishimura K, Itoh H (1992) High-resolution computed tomographic features of bronchiolitis obliterans organizing pneumonia. Chest 102:S26-S31

Oh YW, Kim YH, Lee NJ, et al. (1994) High-resolution CT appearance of miliary tuberculosis. J Comput Assist Tomogr 18:862-866

Parker RG (1990) Radiation-induced cancer as a factor in clinical decision making (the 1989 ASTRO Gold Medal address). Int J Radiat Oncol Biol Phys 18:993-1000

Patz EF Jr, Peters WP, Goodman PC (1994) Pulmonary drug toxicity following high-dose chemotherapy with autologous bone marrow transplantation: CT findings in 20 cases. J Thorac Imaging 9:129-134

Penniment MG, O'Brien PC (1994) Pneumothorax following thoracic radiation therapy for Hodgkin's disease. Thorax 49:936-937

Peylan-Ramu N, Haddy TB, Jones E, et al. (1989) High frequency of benign mediastinal uptake of gallium-67 after completion of chemotherapy in children with high-grade non-Hodgkin's lymphoma. J Clin Oncol 12:1800-1806
Pezner RD, Horak DA, Sayegh HO, et al. (1990) Spontaneous pneumothorax in patients irradiated for Hodgkin's disease and other malignant lymphomas. Int J Radiat Oncol Biol Phys 18:193-198

Popovsky MA (2001) Transfusion and lung injury. Transfus Clin Biol 8:272-277

Popovsky MA, Moore SB (1985) Diagnostic and pathogenetic considerations in transfusion-related acute lung injury. Transfusion 25:573-577

Preidler KW, Szolar DM, Moelleken, et al. (1996) Distribution pattern of computed tomography findings in patients with bronchiolitis obliterans organizing pneumonia. Invest Radiol 31:251-255

Primack SL, Hartman TE, Ikezoe J, et al. (1993) Acute interstitial pneumonia: radiographic and CT findings in nine patients. Radiology 188:817-820

Primack SL, Hartman TE, Lee KS, et al. (1994) Pulmonary nodules and the CT halo sign. Radiology 190:513-515

Primack SL, Miller RR, Müller NL, et al. (1995) Diffuse pulmonary hemorrhage: Clinical, pathologic, and imaging features. AJR Am J Roentgenol 164:295-300

Primack SL, Müller NL (1994) High-resolution computed tomography in acute diffuse lung disease in the immunocompromised patient. Radiol Clin North Am 32:731-744

Qanadli SD, El Hajjam M, Mignon F, et al. (1999) Helical CT phlebography of the superior vena cava: diagnosis and evaluation of venous obstruction. AJR Am J Roentgenol 172:1327-1333

Rahmouni A, Divine M, Lepage E, et al. (2001) Mediastinal lymphoma: quantitative changes in gadolinium enhancement at MR imaging after treatment. Radiology 219: 621-628

Reinders JG, Heijmen BJ, Olofsen-van Acht MJ, et al. (1999) Ischemic heart disease after mantlefield irradiation for Hodgkin's disease in long-term follow-up. Radiother Oncol 51:35-42

Rivero H, Gaisie G, Bender TM, et al. (1984) Calcified mediastinal lymph nodes in Hodgkin's disease. Pediatr Radiol 14:11-13

Roebuck DJ, Nicholls WD, Bernard EJ, et al. (1998) Misleading leads. Thallium-201 uptake in rebound thymic hyperplasia. Med Pediatr Oncol 30:297-300

Rosanowski F, Tigges M, Eysholdt U (1995) Esophagomediastinal fistula and recurrent laryngeal nerve paralysis after radiotherapy of Hodgkin's disease. Laryngorhinootologie 74:516-517

Rossi SE, Erasmus JJ, McAdams HP, et al. (2000) Pulmonary drug toxicity: radiologic and pathologic manifestations. Radiographics 20:1245-1259

Rossleigh MA, Smith J, Straus DJ, et al. (1986) Osteonecrosis in patients with malignant lymphoma. A review of 31 cases. Cancer 58:1112-1116

Roswit B, White DC (1977) Severe radiation injuries of the lung. Am J Roentgenol 129:127-136

Rowinsky EK, Abeloff MD, Wharam MD (1985) Spontaneous pneumothorax following thoracic irradiation. Chest 88 : 703-708

Rubin P, Casarett GW (1968) Clinical radiation pathology, 1st edn. WB Saunders, Philadelphia, London, Toronto

Sider L, Westcott MA (1994) Pulmonary manifestations of cryptococcosis in patients with AIDS: CT features. J Thorac Imag 9:78-84

Silliman CC, Boshkov LK, Mehdizadehkashi Z, et al. (2003) 
Transfusion-related acute lung injury: epidemiology and a prospective analysis of etiologic factors. Blood 101: $454-462$

Smith J (1982) Radiation-induced sarcoma of bone: clinical and radiographic findings in 43 patients irradiated for soft tissue neoplasms. Clin Radiol 33:205-221

Souba WW, McKenna RJ Jr, Benjamin R, et al. (1986) Radiation-induced sarcoma of the chest wall. Cancer 57: 610-615

Soubani AO, Miller KB, Hassoun PN (1996) Pulmonary complications of bone marrow transplantation. Chest 109: 1066-1077

Spaepen K, Mortelmans L (2001) Evaluation of treatment response in patients with lymphoma using [18F]FDGPET: differences between non-Hodgkin's lymphoma and Hodgkin's disease. Q J Nucl Med 45:269-273

Stein JS, Jacobson JH (1993) Axillary-contralateral brachial artery bypass for radiation-induced occlusion of the subclavian artery. Cardiovasc Surg 2:146-148

Stewart JR, Fajardo LF (1984) Radiation-induced heart disease: an update. Prog Cardiovasc Dis 27:173-194

Stewart JR, Fajardo LF, Gillette SM, et al. (1995) Radiation injury to the heart. Int J Radiat Oncol Biol Phys 31: 1205-1211

Tanaka N, Matsumoto T, Miura G, Emoto T, Matsunaga N (2002) HRCT findings of chest complications in patients with leukemia. Eur Radiol 12:1512-1522

Tenholder MF, Hooper RG (1980) Pulmonary infiltrates in leukemia. Chest 78:468-473

Thyagarajan D, Cascino T, Harms G (1995) Magnetic resonance imaging in brachial plexopathy of cancer. Neurology 45:421-427

Totterman KJ, Pesonen E, Siltanen P, et al. (1983) Radiationinduced chronic heart disease. Chest 83:875-878

Tredaniel J, Brice P, Lepage E, et al. (1992) The significance of a residual mediastinal mass following treatment for aggressive non-Hodgkin's lymphomas. Eur Respir J 5:170-173

Tucker MA, D’Angio GJ, Boice JD Jr, et al. (1987) Bone sarcomas linked to radiotherapy and chemotherapy in children. N Engl J Med 317:588-593

Van Leeuwen FE, Klokman WJ, Hagenbeek A, et al. (1994) Second cancer risk following Hodgkin's disease: a 20-year follow-up study. J Clin Oncol 12:312-325
Van Leeuwen FE, Klokman WJ, Stovall M, et al. (1995) Roles of radiotherapy and smoking in lung cancer following Hodgkin's disease. J Natl Cancer Inst 87:1530-1537

Van Leeuwen FE, Klokman WJ, Veer MB, et al. (2000) Long term risk of second malignancy in survivors of Hodgkin's disease treated during adolescence or young adulthood. J Clin Oncol 18:487-497

Vlachaki MT, Ha CS, Hagemeister FB, et al. (1998) Stage I Hodgkin disease: radiation therapy and chemotherapy at the University of Texas M.D. Anderson Cancer Center, 1967-1997. Radiology 208:739-747

Webb WR, Müller NL, Naidich DP (1996) Diseases characterized primarily by parenchymal opacification. In: Webb WR, Müller NL, Naidich DP (eds) High-resolution CT of the lung. Lippincott-Raven, Philadelphia, New York, pp 193-225

Winn WC, Chandler FW (1994) Bacterial infections. In: Dail DH, Hammar SP (eds) Pulmonary pathology. SpringerVerlag, New York, pp 255-330

Worthy SA, Flint JD, Müller NL (1997a) Pulmonary complications after bone marrow transplantation: High-resolution CT and pathologic findings. Radiographics 17:1359-1371

Worthy SA, Park CS, Kim JS, et al. (1997b) Bronchiolitis obliterans after lung transplantation: high-resolution CT findings in 15 patients. AJR Am J Roentgenol 169:673-677

Wouter van Es H, Engelen AM, Witkamp TD, et al. (1997) Radiation-induced brachial plexopathy: MR imaging. Skeletal Radiol 26:284-288

Yahalom J, Hasin Y, Fuks Z, et al. (1983) Acute myocardial infarction with normal coronary angiogram after mantle irradiation therapy for Hodgkin's disease. Cancer 52: 637-641

Yahalom J, Petrec JA, Biddinger PW, et al. (1992) Breast cancer in patients irradiated for Hodgkin disease: a clinical and pathologic analysis of 45 events in 37 patients. J Clin Oncol 10:1674-1681

Zinner SH (1999) Changing epidemiology of infections in patients with neutropenia and cancer: emphasis on gram-positive and resistant bacteria. Clin Infect Dis 29: 490-494

Zinzani PL, Monetti N, Zompatori M, et al. (2001) Importance of gallium scan restaging for curative treatment of mediastinal lymphomas. Haematologica 86:1229-1230 